\title{
A Solution to the Navier-Stokes Inequality with an Internal Singularity
}

\author{
Vladimir Scheffer* \\ Department of Mathematics, Rutgers University, New Brunswick, NJ 08903 USA
}

\begin{abstract}
We consider weak solutions to the time dependent Navier-Stokes equations of incompressible fluid flow in three dimensional space with an external force that always acts against the direction of the flow. We show that there exists a solution with an internal singularity. The speed of the flow reaches infinity at this singular point. In addition, the solution has finite kinetic energy.
\end{abstract}

\section{Section 1. Introduction}

The purpose of this paper is to prove Theorem 1.1 below. The statement of this theorem is followed by an informal explanation of what it says.

Definition. If $f$ is a function defined on an open subset of $R^{3} \times R$, then the laplacian and the gradient of $f$ will involve only the $R^{3}$ variables. Thus,

$$
\Delta f(x, t)=\sum_{i=1}^{3} \frac{\partial^{2} f}{\partial x_{i}^{2}}(x, t) \quad \text { and } \quad \nabla f(x, t)=\left(\frac{\partial f}{\partial x_{1}}(x, t), \frac{\partial f}{\partial x_{2}}(x, t), \frac{\partial f}{\partial x_{3}}(x, t)\right) .
$$

The norm $|f|$ will always be the euclidean norm. For example, in (1.7) we have $|\nabla u|^{2}=\sum_{i=1}^{3} \sum_{j=1}^{3}\left(\frac{\partial u_{i}}{\partial x_{j}}\right)^{2}$.

Theorem 1.1. There exist functions $u: R^{3} \times[0, \infty) \rightarrow R^{3}$ and $p: R^{3} \times[0, \infty) \rightarrow R$ with the following properties:

there is a compact set $K \subset R^{3}$ such that $u(x, t)=0 \quad$ for all $x \notin K$,

for fixed $t$, the function $u_{t}: R^{3} \rightarrow R^{3}$ defined by $u_{t}(x)=u(x, t)$ is a $C^{\infty}$ function,

$$
\begin{gathered}
\sum_{i=1}^{3} \frac{\partial u_{i}}{\partial x_{i}}(x, t)=0 \\
p(x, t)=\int_{R^{3}} \sum_{i=1}^{3} \sum_{j=1}^{3} \frac{\partial u_{j}}{\partial x_{i}}(y, t) \frac{\partial u_{i}}{\partial x_{j}}(y, t)(4 \pi|x-y|)^{-1} d y,
\end{gathered}
$$

* The author was supported in part by a Sloan Foundation Fellowship 
there exists $M<\infty$ such that $\left\|u_{t}\right\|_{2}<M$ for all $t,\left(u_{t}\right.$ is defined in (1.2)),

$$
|\nabla u|^{2},|u|^{3} \text { and }|u||p| \text { are integrable, }
$$

if $\phi: R^{3} \times(0, \infty) \rightarrow R$ is a $C^{\infty}$ function with compact support and $\phi \geqq 0$, then

$$
\int_{0}^{\infty} \int_{R^{3}}|\nabla u|^{2} \phi \leqq \int_{0}^{\infty} \int_{R^{3}}\left(2^{-1}|u|^{2}+p\right) u \cdot \nabla \phi+\int_{0}^{\infty} \int_{R^{3}} 2^{-1}|u|^{2}\left(\frac{\partial \phi}{\partial t}+\Delta \phi\right),
$$

$u$ is not essentially bounded on any neighborhood of the point $(0,1)$

(which is an interior point of the domain of $u$ ).

Before explaining this, we digress to place this theorem in the context of other papers. Let $S(u)$ be the set of points $(x, t) \in R^{3} \times(0, \infty)$ satisfying the following condition: If $U$ is a neighborhood of $(x, t)$ (in the natural topology of $R^{3} \times(0, \infty)$ ), then $u$ is not essentially bounded on $U$. The first theorem in [4] implies the following: if $u: R^{3} \times[0, \infty) \rightarrow R^{3}$ and $p: R^{3} \times[0, \infty) \rightarrow R$ satisfy (1.1)-(1.7), then the Hausdorff dimension of $\mathrm{S}(u)$ is at most 2. The definition of Hausdorff dimension is given in [3], starting on page 171 . Under slightly different conditions, $L$. Caffarelli, R. Kohn and L. Nirenberg have shown in [1] that the Hausdorff dimension of $\mathrm{S}(u)$ is at most 1 . Theorem 1.1, which says $(0,1) \in \mathrm{S}(u)$, shows that conditions (1.1)-(1.7) are not enough to imply that $\mathbf{S}(u)$ is empty.

I have found examples in which (1.1)-(1.7) hold and the Hausdorff dimension of $\mathrm{S}(u)$ is equal to $1-\varepsilon$ for any preassigned $\varepsilon$ between 0 and 1 . This shows that the Caffarelli, Kohn, Nirenberg estimate is the best possible. Since these examples are an order of magnitude more complex than what is presented in this paper, I am postponing publication until I can bring the exposition into a more readable form.

Now we give an informal discussion of the connection between (1.1)-(1.8) and the Navier-Stokes equations. If $R^{3}$ is space, $[0, \infty)$ is time, and $u: R^{3} \times$ $[0, \infty) \rightarrow R^{3}$ is a solution to the Navier-Stokes equations of incompressible, time-dependent fluid flow with viscosity $=1$, then we have the classical equations

$$
\frac{\partial}{\partial t} u_{i}=-\sum_{j=1}^{3} u_{j} \frac{\partial u_{i}}{\partial x_{j}}-\frac{\partial p}{\partial x_{i}}+\Delta u_{i} \text { and } \sum_{i=1}^{3} \frac{\partial u_{i}}{\partial x_{i}}=0,
$$

where $p: R^{3} \times[0, \infty) \rightarrow R$ is the pressure. In this paper we consider solutions to the Navier-Stokes inequality, which can be written as (1.10) and (1.11):

$$
\begin{gathered}
\frac{\partial}{\partial t} u_{i}=-\sum_{j=1}^{3} u_{j} \frac{\partial u_{i}}{\partial x_{i}}-\frac{\partial p}{\partial x_{i}}+\Delta u_{i}+f_{i}, \quad \sum_{i=1}^{3} \frac{\partial u_{i}}{\partial x_{i}}=0, \\
\sum_{i=1}^{3} f_{i} u_{i} \leqq 0, \quad \sum_{i=1}^{3} \frac{\partial f_{i}}{\partial x_{i}}=0,
\end{gathered}
$$

where $f: R^{3} \times[0, \infty) \rightarrow R^{3}$ is a function and $u, p$ have the same domain and range as before. Condition (1.10) says that there is an external force $f$ acting on the viscous, incompressible fluid. The first part of (1.11) says that this force does not 
increase the magnitude of the velocity vector at any point in space-time. We will give an informal proof of the following:

Assertion 1. Properties (1.3), (1.4), (1.7) imply that the Navier-Stokes inequality holds in a weak sense.

This says that Theorem 1.1 can be rewritten informally as follows:

Assertion 2. There exists a solution to the Navier-Stokes inequality with an internal singularity.

What we would really like to do is to prove the following conjecture:

Conjecture 1. There exists a solution to the Navier-Stokes equations with an internal singularity.

This paper is a step towards proving this conjecture. At first glance, it seems that the presence of $f$ makes it more difficult to come up with an example of an interior singularity. After all, the inequality $\sum_{i=1}^{3} f_{i} u_{i} \leqq 0$ only makes it harder for $u$ to become unbounded. The force $f$ tends to push down on $|u|$. This argument seems to imply that Theorem 1.1 is at least as strong as Conjecture 1. Actually, the introduction of $f$ gives us more freedom in constructing an example because we can decrease $|u|$ at some points in order to create a situation in which the pressure term causes an increase in $|u|$ at some other points at a later time. In summary, Conjecture 1 is more difficult to prove than Theorem 1.1, but this theorem suggests that Conjecture 1 should be true.

Now we present the informal proof of Assertion 1. The identity $u \cdot \Delta u=$ $2^{-1} \Delta|u|^{2}-|\nabla u|^{2},(1.3),(1.7)$ and integration by parts give us

$$
\int_{0}^{\infty} \int_{R^{3}}\left(u \cdot \frac{\partial u}{\partial t}+u \cdot \nabla\left(2^{-1}|u|^{2}+p\right)-u \cdot \Delta u\right) \phi \leqq 0
$$

if $\phi: R^{3} \times(0, \infty) \rightarrow R$ is $C^{\infty}$ with compact support and $\phi \geqq 0$. This is a weak form of

$$
u \cdot \frac{\partial u}{\partial t}+u \cdot \nabla\left(2^{-1}|u|^{2}+p\right)-u \cdot \Delta u \leqq 0
$$

which can be rewritten as

$$
u \cdot \frac{\partial u}{\partial t}+u \cdot\left(\sum_{j=1}^{3} u_{j} \frac{\partial u}{\partial x_{j}}\right)+u \cdot \nabla p-u \cdot \Delta u \leqq 0 .
$$

Setting

$$
f=\frac{\partial u}{\partial t}+\sum_{j=1}^{3} u_{j} \frac{\partial u}{\partial x_{j}}+\nabla p-\Delta u
$$

we conclude the first part of (1.11). If we take the divergence of (1.12) and use (1.3), then we obtain

$$
\sum_{i=1}^{3} \frac{\partial f_{i}}{\partial x_{i}}=\sum_{i=1}^{3} \sum_{j=1}^{3} \frac{\partial u_{j}}{\partial x_{i}} \frac{\partial u_{i}}{\partial x_{j}}+\Delta p
$$


Since (1.4) yields $\Delta p=-\sum_{i=1}^{3} \sum_{j=1}^{3} \frac{\partial u_{j}}{\partial x_{i}} \frac{\partial u_{i}}{\partial x_{j}}$, the above implies the second part of (1.11). Property (1.10) follows from (1.12) and (1.3).

It should be emphasized that the $f$ in the example is very singular. This means that our solution is nonphysical. It is possible to smooth $f$ a bit and make it $C^{\infty}$ on $R^{3} \times(0,1)$, but $f$ would still be a bizarre function that would not come up in real life situations. Nevertheless, the example shows that energy-based methods are not enough to prove the regularity of weak solutions to the Navier-Stokes equations. After all, these methods are based on (1.7) and (1.3) rather than (1.9).

The key ideas in the construction are the following:

(A) Changing the Direction of $u$ at Discrete Times. If $u$ is a solution on a time interval $\left(t_{0}, t_{1}\right)$ and $u^{\prime}$ is one on $\left(t_{1}, t_{2}\right)$, then they combine to give a solution of the Navier-Stokes inequality on $\left(t_{0}, t_{2}\right)$ iff

$$
\left|u\left(x, t_{1}\right)\right|^{2} \geqq\left|u^{\prime}\left(x, t_{1}\right)\right|^{2} \quad \text { for almost all } x \in R^{3} .
$$

(B) Changing the Viscosity. We construct $u$ in such a way that it is a solution to the Navier-Stokes inequality for all sufficiently small viscosities. Then we make the viscosity equal to 1 with a change of scale.

(C) Self-Similarity. If one could solve

$$
2^{-1} w+2^{-1} x \cdot \nabla w+w \cdot \nabla w-v \Delta w+\nabla q=g, \quad \nabla \cdot w=0
$$

for some $w(x), g(x)$ with $w \cdot g \leqq 0$, then $u=(1-t)^{-1 / 2} w\left((1-t)^{-1 / 2} x\right)$ would be a singular solution of the Navier-Stokes inequality. The construction used in this paper is different, but similar in spirit.

(D) Nonlocal Effects. The example has compactly supported velocity $u=u^{\prime}+u^{\prime \prime}$ with $\operatorname{spt}\left(u^{\prime}\right) \cap \operatorname{spt}\left(u^{\prime \prime}\right)=\varnothing$. The direction of $u^{\prime}$ is chosen to oscillate in a way that makes the magnitude of $u^{\prime \prime}$ grow, via the nonlocal effect of the pressure.

\section{Section 2. Additional Definitions and Preliminaries}

Definition. If $U$ is an open subset of $R^{m}$, then $C_{c}^{\infty}\left(U, R^{n}\right)$ is the set of $C^{\infty}$ functions from $U$ into $R^{n}$ with compact support. If $f \in C_{c}^{\infty}\left(U, R^{n}\right)$, then the support of $f$ will be denoted spt $(f)$. If $\left\{f_{1}, f_{2}\right\} \subset C_{c}^{\infty}\left(R^{3}, R\right), f_{i} \geqq 0, a<b$ and $v>0$ then the 5-tuple $\left(f_{1}, f_{2}, a, b, v\right)$ is called admissible when there exist functions $u: R^{3} \times[a, b] \rightarrow R^{3}$ and $p: R^{3} \times[a, b] \rightarrow R$ satisfying (1.1)-(1.6) and the condition

$$
\begin{gathered}
\int_{R^{3}} 2^{-1}\left(f_{2}(x)\right)^{2} \phi(x, b) d x-\int_{R^{3}} 2^{-1}\left(f_{1}(x)\right)^{2} \phi(x, a) d x+\int_{a}^{b} \int_{R^{3}} v|\nabla u|^{2} \phi \\
\leqq \int_{a}^{b} \int_{R^{3}}\left(2^{-1}|u|^{2}+p\right) u \cdot \nabla \phi+\int_{a}^{b} \int_{R^{3}} 2^{-1}|u|^{2}\left(\frac{\partial \phi}{\partial t}+\nu \Delta \phi\right)
\end{gathered}
$$

for every $\phi \in C_{c}^{\infty}\left(R^{3} \times R, R\right)$ with the property $\phi \geqq 0$. We set

$$
P=\left\{\left(x_{1}, x_{2}\right) \in R^{2}: x_{2}>0\right\} \text {. }
$$


If $c=\left(c_{1}, c_{2}\right) \in R^{2}$ and $c_{1}^{2}+c_{2}^{2}=1$, then $R_{c}: R^{3} \rightarrow R^{3}$ is the rotation

$$
R_{c}\left(x_{1}, x_{2}, x_{3}\right)=\left(x_{1}, c_{1} x_{2}-c_{2} x_{3}, c_{1} x_{3}+c_{2} x_{2}\right)
$$

about the $x_{1}$ axis. If $\left\{g_{1}, g_{2}\right\} \subset C_{c}^{\infty}(P, R), g_{i} \geqq 0, a<b$ and $v>0$, then the 5-tuple $\left(g_{1}, g_{2}, a, b, v\right)$ is called $P$-admissible if there exists $\left\{f_{1}, f_{2}\right\} \subset C_{c}^{\infty}\left(R^{3}, R\right)$ such that

If $c \in R^{2}, \quad|c|=1$ and $\left(x_{1}, x_{2}\right) \in P$, then $f_{i}\left(R_{c}\left(x_{1}, x_{2}, 0\right)\right)=g_{i}\left(x_{1}, x_{2}\right)$, $\left(f_{1}, f_{2}, a, b, v\right)$ is admissible. If $f \in C_{c}^{\infty}(P, R), v=\left(v_{1}, v_{2}\right) \in C_{c}^{\infty}\left(P, R^{2}\right), f \geqq 0$, and $f(x)>|v(x)|$ holds for all $x \in \operatorname{spt}(v)$, then $p^{*}[v, f]$ is the $C^{\infty}$ function from $R^{3}$ into $R$ defined by

$$
p^{*}[v, f](x)=\int_{R^{3}} \sum_{i=1}^{3} \sum_{j=1}^{3}\left(\frac{\partial}{\partial x_{i}} u_{j}[v, f]\right)(y)\left(\frac{\partial}{\partial x_{j}} u_{i}[v, f]\right)(y)(4 \pi|x-y|)^{-1} d y,
$$

where $u[v, f]=\left(u_{1}[v, f], u_{2}[v, f], u_{3}[v, f]\right) \in C_{c}^{\infty}\left(R^{3}, R^{3}\right)$ is given by

$$
\begin{aligned}
u[v, f]\left(x_{1}, x_{2}, 0\right)= & \left(v_{1}\left(x_{1}, x_{2}\right), v_{2}\left(x_{1}, x_{2}\right),\left(\left(f\left(x_{1}, x_{2}\right)\right)^{2}\right.\right. \\
& \left.\left.-\left|v\left(x_{1}, x_{2}\right)\right|^{2}\right)^{1 / 2}\right) \quad \text { if }\left(x_{1}, x_{2}\right) \in P,
\end{aligned}
$$

$u[v, f]\left(R_{c}\left(x_{1}, x_{2}, 0\right)\right)=R_{c}\left(u[v, f]\left(x_{1}, x_{2}, 0\right)\right) \quad$ if $c \in R^{2},|c|=1,\left(x_{1}, x_{2}\right) \in P$,

$u[v, f]\left(x_{1}, 0,0\right)=0$.

Note that $u$ equals 0 in a neighborhood of the $x_{1}$ axis. We also set

$$
p[v, f]\left(x_{1}, x_{2}\right)=p^{*}[v, f]\left(x_{1}, x_{2}, 0\right) \text { if }\left(x_{1}, x_{2}\right) \in P .
$$

If $A$ and $B$ are sets we define $A \sim B=\{x \in A: x \notin B\}$. If $f \in C_{c}^{\infty}(P, R)$ we set

$$
L(f)\left(x_{1}, x_{2}\right)=\Delta f\left(x_{1}, x_{2}\right)+x_{2}^{-1}\left(\frac{\partial f}{\partial x_{2}}\left(x_{1}, x_{2}\right)\right)-x_{2}^{-2} f\left(x_{1}, x_{2}\right) \quad \text { if }\left(x_{1}, x_{2}\right) \in P .
$$

We will often encounter repeated indices (for example, in (2.6)). These indices are not summed unless there is a summation sign. In other words, the summation convention for repeated indices is never used. Furthermore, the function $v_{i}$ in (2.3) and (3.2) is not a component of a vector valued function. Rather, we have two unrelated functions, $v_{1}$ and $v_{2}$, and these functions have components $v_{11}, v_{12}$ and $v_{21}, v_{22}$, respectively.

Lemma 2.1. Suppose that $a, b, J, C_{1}, C_{2}, C_{1}^{\prime}, C_{2}^{\prime}, S_{1}, S_{2}, \eta, v_{1}, v_{2}, q_{1}, q_{2}$ satisfy conditions (2.1)-(2.9):

$$
\begin{gathered}
a<b, \quad J \text { is an open set containing }[a, b], \\
C_{i}^{\prime} \subset C_{i} \subset P, \quad C_{i} \text { and } C_{i}^{\prime} \text { are compact, } C_{1} \text { and } C_{2} \text { are disjoint, } \\
S_{i} \in\{1,-1\}, \quad \eta>0, \quad v_{i}=\left(v_{i 1}, v_{i 2}\right) \in C_{c}^{\infty}\left(P, R^{2}\right), \quad \operatorname{spt}\left(v_{i}\right) \subset C_{i}^{\prime}, \\
q_{i}: P \times J \rightarrow R \text { is } a C^{\infty} \text { function, } \quad q_{i}(x, t)=0 \quad \text { if } x \notin C_{i}, \\
q_{i} \geqq 0, \quad q_{i}(x, t)>\left|v_{i}(x)\right| \quad \text { if } x \in \operatorname{spt}\left(v_{i}\right),
\end{gathered}
$$

If $x \in C_{i}^{\prime}$ then, using the notation $q_{i, t}(x)=q_{i}(x, t)$, we have $\frac{\partial}{\partial t} 2^{-1}\left(q_{i}(x, t)\right)^{2}$

$$
\leqq-\eta-S_{i} v_{i}(x) \cdot \nabla\left(2^{-1}\left(q_{i, t}\right)^{2}+p\left[v_{1}, q_{1, t}\right]+p\left[v_{2}, q_{2, t}\right]\right)(x)
$$




$$
\begin{gathered}
\frac{\partial}{\partial t} 2^{-1}\left(q_{i}(x, t)\right)^{2} \leqq 0 \quad \text { if } x \notin C_{i}^{\prime}, \\
L\left(q_{i, t}\right)(x) \geqq 0 \quad \text { if } x \notin C_{i}^{\prime}(\operatorname{see}(2.6)), \\
x_{2} \frac{\partial}{\partial x_{1}} v_{i 1}\left(x_{1}, x_{2}\right)+x_{2} \frac{\partial}{\partial x_{2}} v_{i 2}\left(x_{1}, x_{2}\right)+v_{i 2}\left(x_{1}, x_{2}\right)=0 .
\end{gathered}
$$

Then there exists $v_{0}>0$ such that the 5-tuple

$$
\left(q_{1, a}+q_{2, a}, q_{1, b}+q_{2, b}, a, b, v\right)
$$

is $P$-admissible for all $v$ satisfying $0<v<v_{0}$ (where $q_{i, t}(x)=q_{i}(x, t)$ ).

Proof. Hypotheses (2.1)-(2.5) and the notation in (2.6) allow us to define $u^{i}: R^{3} \times J \rightarrow R^{3}$ and $p^{i}: R^{3} \times J \rightarrow R$ for $i=1,2$ using the formulas

$$
u^{i}(x, t)=S_{i} u\left[v_{i}, q_{i, t}\right](x), \quad p^{i}(x, t)=p^{*}\left[v_{i}, q_{i, t}\right](x) .
$$

If $E$ is a subset of $P$ we define $R(E) \subset R^{3}$ as follows:

$$
R(E)=\left\{R_{c}\left(x_{1}, x_{2}, 0\right): c \in R^{2}, \quad|c|=1, \quad\left(x_{1}, x_{2}\right) \in E\right\} .
$$

Using (2.1)-(2.4) we obtain

$$
u^{i} \text { is a } C^{\infty} \text { function on } R^{3} \times J, u^{i}(x, t)=0 \text { if } x \notin R\left(C_{i}\right) \text {. }
$$

In addition, (2.11) and (2.2) imply

$$
R\left(C_{i}^{\prime}\right) \subset R\left(C_{i}\right), R\left(C_{i}\right) \text { and } R\left(C_{i}^{\prime}\right) \text { are compact, } R\left(C_{1}\right) \text { and } R\left(C_{2}\right) \text { are disjoint. }
$$

We let $p: R^{3} \times J \rightarrow R$ be the $C^{\infty}$ function given by

$$
p(x, t)=\int_{R^{3}} \sum_{i=1}^{3} \sum_{j=1}^{3} \frac{\partial}{\partial x_{i}}\left(u_{j}^{1}+u_{j}^{2}\right)(y, t) \frac{\partial}{\partial x_{j}}\left(u_{i}^{1}+u_{i}^{2}\right)(y, t)(4 \pi|x-y|)^{-1} d y .
$$

Using (2.12), (2.13) we find $\partial / \partial x_{i} u_{j}^{m}(y, t) \partial / \partial x_{j} u_{i}^{n}(y, t)=0$ if $m \neq n$. This fact, the identity $\left(S_{i}\right)^{2}=1$ (see (2.3)), and (2.10), (2.14) imply

$$
\begin{aligned}
p(x, t) & =p^{*}\left[v_{1}, q_{1, t}\right](x)+p^{*}\left[v_{2}, q_{2, t}\right](x)=\left(p^{1}+p^{2}\right)(x, t), \text { hence } \\
p\left(x_{1}, x_{2}, 0, t\right) & =p\left[v_{1}, q_{1, t}\right]\left(x_{1}, x_{2}\right)+p\left[v_{2}, q_{2, t}\right]\left(x_{1}, x_{2}\right) \quad \text { if }\left(x_{1}, x_{2}\right) \in P .
\end{aligned}
$$

From (2.12), (2.13), (2.10), (2.3) we conclude

$$
\begin{aligned}
\left|\left(u^{1}+u^{2}\right)\left(x_{1}, x_{2}, 0, t\right)\right|^{2} & =\left|u^{1}\left(x_{1}, x_{2}, 0, t\right)\right|^{2}+\left|u^{2}\left(x_{1}, x_{2}, 0, t\right)\right|^{2} \\
& =\left(q_{1}\left(x_{1}, x_{2}, t\right)\right)^{2}+\left(q_{2}\left(x_{1}, x_{2}, t\right)\right)^{2} \text { if }\left(x_{1}, x_{2}\right) \in P .
\end{aligned}
$$

If $x \in C_{1}^{\prime} \cup C_{2}^{\prime}$ then (2.6), the disjointness of $C_{1}$ and $C_{2}$, and (2.2)-(2.4) yield

$$
\begin{aligned}
& \frac{\partial}{\partial t} 2^{-1}\left(\left(q_{1}(x, t)\right)^{2}+\left(q_{2}(x, t)\right)^{2}\right) \\
& \quad \leqq \\
& \quad-\eta-\left(S_{1} v_{1}(x)+S_{2} v_{2}(x)\right) \cdot \nabla\left(2 ^ { - 1 } \left(\left(q_{1, t}\right)^{2}\right.\right. \\
& \left.\left.\quad+\left(q_{2, t}\right)^{2}\right)\right)(x)-\left(S_{1} v_{1}(x)+S_{2} v_{2}(x)\right) \cdot \nabla\left(p\left[v_{1}, q_{1, t}\right]+p\left[v_{2}, q_{2, t}\right]\right)(x) .
\end{aligned}
$$


Combining this with (2.16), the identity

$$
u_{k}^{i}\left(x_{1}, x_{2}, 0, t\right)=S_{i} v_{i k}\left(x_{1}, x_{2}\right) \text { for } k=1,2
$$

(see (2.10)) and (2.15), we find that every $\left(x_{1}, x_{2}\right) \in C_{1}^{\prime} \cup C_{2}^{\prime}$ satisfies

$$
\begin{aligned}
& \frac{\partial}{\partial t} 2^{-1}\left|u^{1}+u^{2}\right|^{2}\left(x_{1}, x_{2}, 0, t\right) \\
& \quad \leqq-\eta-\sum_{k=1}^{2}\left(u_{k}^{1}+u_{k}^{2}\right)\left(x_{1}, x_{2}, 0, t\right) \frac{\partial}{\partial x_{k}}\left(2^{-1}\left|u^{1}+u^{2}\right|^{2}+p\right)\left(x_{1}, x_{2}, 0, t\right) .
\end{aligned}
$$

The rotational symmetry of $\left|u^{1}+u^{2}\right|^{2}$ and $p$ about the $x_{1}$ axis implies

$$
\frac{\partial}{\partial x_{3}}\left(2^{-1}\left|u^{1}+u^{2}\right|^{2}+p\right)\left(x_{1}, x_{2}, 0, t\right)=0 \quad \text { if }\left(x_{1}, x_{2}\right) \in P \text {. }
$$

Hence, using the 3-dimensional gradient $\nabla$, we obtain

$$
\begin{aligned}
& \frac{\partial}{\partial t} 2^{-1}\left|u^{1}+u^{2}\right|^{2}\left(x_{1}, x_{2}, 0, t\right) \\
& \quad \leqq-\eta-\left(u^{1}+u^{2}\right)\left(x_{1}, x_{2}, 0, t\right) \cdot \nabla\left(2^{-1}\left|u^{1}+u^{2}\right|^{2}+p\right)\left(x_{1}, x_{2}, 0, t\right)
\end{aligned}
$$

if $\left(x_{1}, x_{2}\right) \in C_{1}^{\prime} \cup C_{2}^{\prime}$. The rotational symmetry and (2.11) allow us to rewrite the above as

$$
\begin{aligned}
& \frac{\partial}{\partial t} 2^{-1}\left|u^{1}+u^{2}\right|^{2}(x, t) \\
& \quad \leqq-\eta-\left(u^{1}+u^{2}\right)(x, t) \cdot \nabla\left(2^{-1}\left|u^{1}+u^{2}\right|^{2}+p\right)(x, t) \text { if } x \in R\left(C_{1}^{\prime}\right) \cup R\left(C_{2}^{\prime}\right) .
\end{aligned}
$$

Since (2.3), (2.13) imply that $\eta$ is positive and $R\left(C_{1}^{\prime}\right) \cup R\left(C_{2}^{\prime}\right)$ is compact, we can use (2.1), (2.12) to find $v_{0}>0$ with the following property:

$$
\begin{aligned}
& \frac{\partial}{\partial t} 2^{-1}\left|u^{1}+u^{2}\right|^{2}(x, t)+v\left|\nabla\left(u^{1}+u^{2}\right)\right|^{2}(x, t) \\
& \quad \leqq-\left(u^{1}+u^{2}\right)(x, t) \cdot \nabla\left(2^{-1}\left|u^{1}+u^{2}\right|^{2}+p\right)(x, t)+v \Delta\left(2^{-1}\left|u^{1}+u^{2}\right|^{2}\right)(x, t) \\
& \quad \text { if } x \in R\left(C_{1}^{\prime}\right) \cup R\left(C_{2}^{\prime}\right), t \in[a, b] \text { and } 0<v<v_{0} .
\end{aligned}
$$

From (2.3), (2.5) we obtain

$$
u\left[v_{i}, q_{i, t}\right]\left(z_{1}, z_{2}, 0\right)=\left(0,0, q_{i, t}\left(z_{1}, z_{2}\right)\right) \text { if }\left(z_{1}, z_{2}\right) \in P \sim\left(C_{1}^{\prime} \cup C_{2}^{\prime}\right) .
$$

If $\left(x_{1}, x_{2}, x_{3}\right)=R_{c}\left(z_{1}, z_{2}, 0\right)$ and $\left(z_{1}, z_{2}\right) \in P$, then we must have

$$
c_{1}=x_{2}\left(x_{2}^{2}+x_{3}^{2}\right)^{-1 / 2}, \quad c_{2}=x_{3}\left(x_{2}^{2}+x_{3}^{2}\right)^{-1 / 2}, \quad z_{1}=x_{1}, \quad z_{2}=\left(x_{2}^{2}+x_{3}^{2}\right)^{1 / 2} \text {. }
$$

The above, (2.19) and (2.11) imply

$$
\begin{aligned}
& u_{3}\left[v_{i}, q_{i, t}\right]\left(x_{1}, x_{2}, x_{3}\right)=c_{1} q_{i, t}\left(z_{1}, z_{2}\right)=x_{2}\left(x_{2}^{2}+x_{3}^{2}\right)^{-1 / 2} q_{i, t}\left(x_{1},\left(x_{2}^{2}+x_{3}^{2}\right)^{1 / 2}\right) \\
& \text { if }\left(x_{1}, x_{2}, x_{3}\right) \in R\left(P \sim\left(C_{1}^{\prime} \cup C_{2}^{\prime}\right)\right) . \text { This fact and }(2.10) \text { yield } \\
& \left(u_{3}^{1}+u_{3}^{2}\right)\left(x_{1}, x_{2}, x_{3}, t\right)=x_{2}\left(x_{2}^{2}+x_{3}^{2}\right)^{-1 / 2}\left(S_{1} q_{1, t}+S_{2} q_{2, t}\right)\left(x_{1},\left(x_{2}^{2}+x_{3}^{2}\right)^{1 / 2}\right)
\end{aligned}
$$


for $\left(x_{1}, x_{2}, x_{3}\right) \in R\left(P \sim\left(C_{1}^{\prime} \cup C_{2}^{\prime}\right)\right)$. This gives us

$$
\Delta\left(u_{3}^{1}+u_{3}^{2}\right)\left(x_{1}, x_{2}, 0, t\right)=\left(S_{1} L\left(q_{1, t}\right)+S_{2} L\left(q_{2, t}\right)\right)\left(x_{1}, x_{2}\right) \quad \text { if }\left(x_{1}, x_{2}\right) \in P \sim\left(C_{1}^{\prime} \cup C_{2}^{\prime}\right) \text {. }
$$

Using (2.19) and (2.10) we get

$$
\left(u^{1}+u^{2}\right)\left(x_{1}, x_{2}, 0, t\right)=\left(0,0,\left(S_{1} q_{1, t}+S_{2} q_{2, t}\right)\left(x_{1}, x_{2}\right)\right) \quad \text { if }\left(x_{1}, x_{2}\right) \in P \sim\left(C_{1}^{\prime} \cup C_{2}^{\prime}\right) .
$$

From (2.20), (2.21), (2.2), (2.4) we obtain

$$
\begin{aligned}
& \left(\left(u^{1}+u^{2}\right) \cdot \Delta\left(u^{1}+u^{2}\right)\right)\left(x_{1}, x_{2}, 0, t\right) \\
& \quad=\left(S_{1} q_{1, t}+S_{2} q_{2, t}\right)\left(x_{1}, x_{2}\right)\left(S_{1} L\left(q_{1, t}\right)+S_{2} L\left(q_{2, t}\right)\right)\left(x_{1}, x_{2}\right) \\
& \quad=\sum_{i=1}^{2}\left(S_{i}\right)^{2} q_{i, t}\left(x_{1}, x_{2}\right) L\left(q_{i, t}\right)\left(x_{1}, x_{2}\right)
\end{aligned}
$$

if $\left(x_{1}, x_{2}\right) \in P \sim\left(C_{1}^{\prime} \cup C_{2}^{\prime}\right)$. Combining this with (2.3), (2.5), (2.8) we find

$$
\left(\left(u^{1}+u^{2}\right) \cdot \Delta\left(u^{1}+u^{2}\right)\right)\left(x_{1}, x_{2}, 0, t\right) \geqq 0 \quad \text { if }\left(x_{1}, x_{2}\right) \in P \sim\left(C_{1}^{\prime} \cup C_{2}^{\prime}\right)
$$

The above, (2.11) and the rotational symmetry of $u^{1}+u^{2}$ imply

$$
\left(\left(u^{1}+u^{2}\right) \cdot \Delta\left(u^{1}+u^{2}\right)\right)(x, t) \geqq 0 \quad \text { if } x \in R\left(P \sim\left(C_{1}^{\prime} \cup C_{2}^{\prime}\right)\right) .
$$

The general formula $\Delta\left(2^{-1}|f|^{2}\right)-|\nabla f|^{2}=f \cdot \Delta f$ and (2.22) imply

$$
\Delta\left(2^{-1}\left|u^{1}+u^{2}\right|^{2}\right)(x, t)-\left|\nabla\left(u^{1}+u^{2}\right)\right|^{2}(x, t) \geqq 0 \quad \text { if } x \in R\left(P \sim\left(C_{1}^{\prime} \cup C_{2}^{\prime}\right)\right) .
$$

From (2.9) and (2.10) we conclude

$$
\sum_{i=1}^{3} \frac{\partial}{\partial x_{i}}\left(u_{i}^{1}+u_{i}^{2}\right)=0
$$

Using (2.16) and (2.7) we find

$$
\frac{\partial}{\partial t} 2^{-1}\left|u^{1}+u^{2}\right|^{2}\left(x_{1}, x_{2}, 0, t\right) \leqq 0 \quad \text { if }\left(x_{1}, x_{2}\right) \in P \sim\left(C_{1}^{\prime} \cup C_{2}^{\prime}\right) .
$$

The above, (2.11) and rotational symmetry yield

$$
\frac{\partial}{\partial t} 2^{-1}\left|u^{1}+u^{2}\right|^{2}(x, t) \leqq 0 \quad \text { if } x \in R\left(P \sim\left(C_{1}^{\prime} \cup C_{2}^{\prime}\right)\right)
$$

If $\left(x_{1}, x_{2}\right) \in P \sim\left(C_{1}^{\prime} \cup C_{2}^{\prime}\right)$ then (2.3), (2.10) imply $\left(u_{k}^{1}+u_{k}^{2}\right)\left(x_{1}, x_{2}, 0, t\right)=0$ for $k=1,2$. This fact and (2.17) yield

$$
\left(\left(u^{1}+u^{2}\right) \cdot \nabla\left(2^{-1}\left|u^{1}+u^{2}\right|^{2}+p\right)\right)\left(x_{1}, x_{2}, 0, t\right)=0 \quad \text { if }\left(x_{1}, x_{2}\right) \in P \sim\left(C_{1}^{\prime} \cup C_{2}^{\prime}\right) .
$$

The above, (2.11) and rotational symmetry imply

$$
\left(\left(u^{1}+u^{2}\right) \cdot \nabla\left(2^{-1}\left|u^{1}+u^{2}\right|^{2}+p\right)\right)(x, t)=0 \quad \text { if } x \in R\left(P \sim\left(C_{1}^{\prime} \cup C_{2}^{\prime}\right)\right) .
$$

Combining (2.23), (2.25), (2.26) we obtain

$$
\frac{\partial}{\partial t} 2^{-1}\left|u^{1}+u^{2}\right|^{2}(x, t)+v\left|\nabla\left(u^{1}+u^{2}\right)\right|^{2}(x, t)
$$




$$
\begin{aligned}
& \leqq-\left(\left(u^{1}+u^{2}\right) \cdot \nabla\left(2^{-1}\left|u^{1}+u^{2}\right|^{2}+p\right)\right)(x, t)+v \Delta\left(2^{-1}\left|u^{1}+u^{2}\right|^{2}\right)(x, t) \\
& \quad \text { if } x \in R\left(P \sim\left(C_{1}^{\prime} \cup C_{2}^{\prime}\right)\right) \text { and } v>0 .
\end{aligned}
$$

Suppose $\phi \in C_{c}^{\infty}\left(R^{3} \times R, R\right)$ satisfies $\phi \geqq 0$ and $v$ satisfies $0<v<v_{0}$. Multiplying (2.18) and (2.27) by $\phi(x, t)$, recalling (2.11) and (2.12), integrating over $R^{3} \times[a, b]$, and applying integration by parts and (2.24) we obtain

$$
\begin{aligned}
& \int_{R^{3}} 2^{-1}\left|u^{1}+u^{2}\right|^{2}(x, b) \phi(x, b) d x-\int_{R^{3}} 2^{-1}\left|u^{1}+u^{2}\right|^{2}(x, a) \phi(x, a) \\
& \cdot d x+\int_{a}^{b} \int_{R^{3}} v\left|\nabla\left(u^{1}+u^{2}\right)\right|^{2} \phi \\
& \quad \leqq \int_{a}^{b} \int_{R^{3}}\left(2^{-1}\left|u^{1}+u^{2}\right|^{2}+p\right)\left(u^{1}+u^{2}\right) \cdot \nabla \phi+\int_{a}^{b} \int_{R^{3}} 2^{-1}\left|u^{1}+u^{2}\right|^{2}\left\{\frac{\partial \phi}{\partial t}+v \Delta \phi\right\} .
\end{aligned}
$$

The conclusion follows from (2.2)-(2.4), (2.10)-(2.12), (2.14), (2.24), the definitions $f_{1}(x)=\left|u^{1}+u^{2}\right|(x, a)$ and $f_{2}(x)=\left|u^{1}+u^{2}\right|(x, b)$, the rotational symmetry of $f_{i}$ and (2.16).

Lemma 2.2. If $a<b<c,\left(g_{1}, g_{2}, a, b, v\right)$ is $P$-admissible and $\left(g_{2}, g_{3}, b, c, v\right)$ is $P$ admissible then $\left(g_{1}, g_{3}, a, c, v\right)$ is $P$-admissible.

Proof. This is elementary.

Lemma 2.3. If $\tau, T, v$ are real numbers, $0<\tau<1, T>0, v>0, a \in R^{3},\left\{f_{1}, f_{2}\right\} \subset$ $C_{c}^{\infty}\left(R^{3}, R\right), f_{i} \geqq 0, f_{1} \neq 0,\left(f_{1}, f_{2}, 0, T, v\right)$ is admissible and the inequality

$$
f_{2}(\tau x+a) \geqq \tau^{-1} f_{1}(x) \text { if } x \in R^{3}
$$

is satisfied, then there exist functions $u: R^{3} \times[0, \infty) \rightarrow R^{3}$ and $p: R^{3} \times[0, \infty) \rightarrow R$ such that (1.1)-(1.6) are satisfied and, in addition, we have (2.29) and (2.30):

if $\phi: R^{3} \times(0, \infty) \rightarrow R$ is $C^{\infty}$ with compact support and $\phi \geqq 0$ then $\int_{0}^{\infty} \int_{R^{3}} v|\nabla u|^{2} \phi$

$$
\leqq \int_{0}^{\infty} \int_{R^{3}}\left(2^{-1}|u|^{2}+p\right) u \cdot \nabla \phi+\int_{0}^{\infty} \int_{R^{3}} 2^{-1}|u|^{2}\left\{\frac{\partial \phi}{\partial t}+v \Delta \phi\right\},
$$

$u$ is not essentially bounded on any neighborhood of the point

$$
\left((1-\tau)^{-1} a,\left(1-\tau^{2}\right)^{-1} T\right)
$$

Proof. Since $\left(f_{1}, f_{2}, 0, T, v\right)$ is admissible, we can find functions $u^{1}: R^{3} \times[0, T] \rightarrow$ $R^{3}$ and $p^{1}: R^{3} \times[0, T] \rightarrow R$ satisfying (1.1)-(1.6) (with $u$ and $p$ replaced by $u^{1}$ and $p^{1}$ ) and the condition

$$
\begin{gathered}
\int_{R^{3}} 2^{-1}\left(f_{2}(x)\right)^{2} \phi(x, T) d x-\int_{R^{3}} 2^{-1}\left(f_{1}(x)\right)^{2} \phi(x, 0) d x+\int_{0}^{T} \int_{R^{3}} v\left|\nabla u^{1}\right|^{2} \phi \\
\leqq \int_{0}^{T} \int_{R^{3}}\left(2^{-1}\left|u^{1}\right|^{2}+p^{1}\right) u^{1} \cdot \nabla \phi+\int_{0}^{T} \int_{R^{3}} 2^{-1}\left|u^{1}\right|^{2}\left\{\frac{\partial \phi}{\partial t}+v \Delta \phi\right\} \\
\quad \text { if } \phi \in C_{c}^{\infty}\left(R^{3} \times R, R\right) \text { and } \phi \geqq 0 .
\end{gathered}
$$


Recalling the hypothesis $0<\tau<1$, we set $T_{j}=\left(\sum_{k=0}^{j-1} \tau^{2 k}\right) T$ for $j=0,1,2, \ldots$ (with the convention $T_{0}=0$ ) and $T_{\infty}=\lim _{j \rightarrow \infty} T_{j}=\left(1-\tau^{2}\right)^{-1} T$. The functions $f_{i}^{j}: R^{3} \rightarrow R, u^{j}: R^{3} \times\left[T_{j-1}, T_{j}\right] \rightarrow R^{3}$ and $\quad p^{j}: R^{3} \times\left[T_{j-1}, T_{j}\right] \rightarrow R$ are defined inductively by the equations

$$
\begin{aligned}
f_{i}^{1} & =f_{i}, f_{i}^{j+1}(x)=\tau^{-1} f_{i}^{j}\left(\tau^{-1}(x-a)\right) \quad \text { if } i=1,2, \\
u^{j+1}(x, t) & =\tau^{-1} u^{j}\left(\tau^{-1}(x-a), \tau^{-2}(t-T)\right), \\
p^{j+1}(x, t) & =\tau^{-2} p^{j}\left(\tau^{-1}(x-a), \tau^{-2}(t-T)\right)
\end{aligned}
$$

for $j \in\{1,2,3, \ldots\}$, where $u^{1}$ and $p^{1}$ are the functions that appear in (2.31). The required functions $u$ and $p$ are given by the following conditions:

if $T_{j-1} \leqq t<T_{j}$, then $u(x, t)=u^{j}(x, t)$ and $p(x, t)=p^{j}(x, t)$,

if $T_{\infty} \leqq t$, then $u(x, t)=0$ and $p(x, t)=0$.

From (2.31) we conclude

$$
\begin{aligned}
& \int_{R^{3}} 2^{-1}\left(f_{2}^{j}(x)\right)^{2} \phi\left(x, T_{j}\right) d x-\int_{R^{3}} 2^{-1}\left(f_{1}^{j}(x)\right)^{2} \phi\left(x, T_{j-1}\right) d x+\int_{T_{j-1}}^{T_{R^{3}}} \int_{B^{3}} v\left|\nabla u^{j}\right|^{2} \phi \\
& \leqq \int_{T_{j-1}}^{T_{R^{3}}} \int\left(2^{-1}\left|u^{j}\right|^{2}+p^{j}\right) u^{j} \cdot \nabla \phi+\int_{T_{j-1}}^{T_{R^{3}}} \int 2^{-1}\left|u^{j}\right|^{2}\left\{\frac{\partial \phi}{\partial t}+v \Delta \phi\right\} \\
& \quad \text { if } \phi \in C_{c}^{\infty}\left(R^{3} \times R, R\right) \quad \text { and } \phi \geqq 0 .
\end{aligned}
$$

Since $f_{i}$ is nonnegative and (2.28) implies $f_{2}^{1}(x) \geqq \tau^{-1} f_{1}^{1}\left(\tau^{-1}(x-a)\right)=f_{1}^{2}(x)$ for all $x \in R^{3}$, we can use induction to show

$$
\left(f_{2}^{j}(x)\right)^{2} \geqq\left(f_{1}^{j+1}(x)\right)^{2} \quad \text { for all } x \in R^{3} \text { and } j=1,2,3, \ldots
$$

The definition of $u^{1}, p^{1}$ and $0<\tau<1$ imply

$$
\begin{gathered}
\|\nabla u\|_{2}^{2}=\sum_{j=1}^{\infty}\left\|\nabla u^{j}\right\|_{2}^{2}=\sum_{j=1}^{\infty} \tau^{j-1}\left\|\nabla u^{1}\right\|_{2}^{2}=(1-\tau)^{-1}\left\|\nabla u^{1}\right\|_{2}^{2}<\infty \\
\|u\|_{3}^{3}=\sum_{j=1}^{\infty}\left\|u^{j}\right\|_{3}^{3}=\sum_{j=1}^{\infty} \tau^{2(j-1)}\left\|u^{1}\right\|_{3}^{3}=\left(1-\tau^{2}\right)^{-1}\left\|u^{1}\right\|_{3}^{3}<\infty \\
\|u p\|_{1}=\sum_{j=1}^{\infty}\left\|u^{j} p^{j}\right\|_{1}=\sum_{j=1}^{\infty} \tau^{2(j-1)}\left\|u^{1} p^{1}\right\|_{1}=\left(1-\tau^{2}\right)^{-1}\left\|u^{1} p^{1}\right\|_{1}<\infty \\
\int_{R^{3}}\left|u^{j}(x, t)\right|^{2} d x \leqq \tau^{j-1} \sup \left\{\int_{R^{3}}\left|u^{1}(x, t)\right|^{2} d x: 0 \leqq t \leqq T\right\} \leqq \tau^{j-1} M^{2}
\end{gathered}
$$

Now (2.32)-(2.34) and $\lim _{j \rightarrow \infty} \tau^{j-1} M^{2}=0$ yield

$-\int_{R^{3}} 2^{-1}\left(f_{1}^{1}(x)\right)^{2} \phi(x, 0) d x+\int_{0}^{\infty} \int_{R^{3}} v|\nabla u|^{2} \phi$ 


$$
\begin{aligned}
\leqq & \sum_{j=1}^{\infty}\left(\int_{R^{3}} 2^{-1}\left(f_{2}^{j}(x)\right)^{2} \phi\left(x, T_{j}\right) d x-\int_{R^{3}} 2^{-1}\left(f_{1}^{j}(x)\right)^{2} \phi\left(x, T_{j-1}\right) d x\right) \\
& +\sum_{j=1}^{\infty} \int_{T_{j-1}}^{T_{j}} \int_{R^{3}} v\left|\nabla u^{j}\right|^{2} \phi \leqq \int_{0}^{\infty} \int_{R^{3}}\left(2^{-1}|u|^{2}+p\right) u \cdot \nabla \phi+\int_{0}^{\infty} \int_{R^{3}} 2^{-1}|u|^{2}\left\{\frac{\partial \phi}{\partial t}+v \Delta \phi\right\}
\end{aligned}
$$

if $\phi \in C_{c}^{\infty}\left(R^{3} \times R, R\right)$ and $\phi \geqq 0$. The above, (2.34) and the properties of $u^{1}, p^{1}$ imply (2.29) and (1.1)-(1.6). It remains to prove (2.30). From (2.28), $f_{i} \geqq 0$ and $f_{1} \neq 0$ we get $f_{2} \neq 0$. Let $x^{\prime} \in R^{3}$ satisfy $\left(f_{2}\left(x^{\prime}\right)\right)^{2}>0$. Choosing $\phi \geqq 0$ such that $\phi\left(x^{\prime}, T\right)>0$ and $\phi(x, 0)=0$ for all $x \in R^{3}$ we see from (2.31) that $u^{1}$ cannot be zero almost everywhere on $R^{3} \times(0, T)$. Conclusion (2.30) follows from this fact, $0<\tau<1$ and the identity

$$
u\left(\tau^{j} x+\left(\sum_{k=0}^{j-1} \tau^{k}\right) a, \tau^{2 j} t+\left(\sum_{k=0}^{j-1} \tau^{2 k}\right) T\right)=\tau^{-j} u^{1}(x, t) \quad \text { if } 0<t<T .
$$

Lemma 2.4. Suppose $\tau, T, v, a_{1}, a_{2}$ are real numbers, $0<\tau<1, T>0, \quad v>0$, $\left\{g_{1}, g_{2}\right\} \subset C_{c}^{\infty}(P, R), g_{i} \geqq 0, g_{1} \neq 0,\left(g_{1}, g_{2}, 0, T, v\right)$ is $P$-admissible and the following property holds: If $\left(x_{1}, x_{2}, x_{3}\right) \in R^{3}$ and $\left(x_{1},\left(x_{2}^{2}+x_{3}^{2}\right)^{1 / 2}\right) \in \operatorname{spt}\left(g_{1}\right)$, then $\left(\tau x_{2}+\right.$ $\left.a_{2}\right)^{2}+\left(\tau x_{3}\right)^{2}>0$ and

$$
g_{2}\left(\tau x_{1}+a_{1},\left(\left(\tau x_{2}+a_{2}\right)^{2}+\left(\tau x_{3}\right)^{2}\right)^{1 / 2}\right) \geqq \tau^{-1} g_{1}\left(x_{1},\left(x_{2}^{2}+x_{3}^{2}\right)^{1 / 2}\right) .
$$

Then Theorem 1.1 is true.

Proof. Let $f_{1}, f_{2}$ be functions in $C_{c}^{\infty}\left(R^{3}, R\right)$ such that $f_{i} \geqq 0, f_{i}\left(R_{c}\left(x_{1}, x_{2}, 0\right)\right)=$ $g_{i}\left(x_{1}, x_{2}\right)$ if $c \in R^{2},|c|=1$ and $\left(x_{1}, x_{2}\right) \in P$, and $\left(f_{1}, f_{2}, 0, T, v\right)$ is admissible. Then the property $f_{i} \geqq 0$ implies $f_{2}\left(\tau x+\left(a_{1}, a_{2}, 0\right)\right) \geqq \tau^{-1} f_{1}(x)$ for $x \in R^{3}$. Lemma 2.3 (with $a=\left(a_{1}, a_{2}, 0\right)$ ) implies the existence of $u: R^{3} \times[0, \infty) \rightarrow R^{3}$ and $p: R^{3} \times[0, \infty) \rightarrow R$ such that (1.1)-(1.6), (2.29) and (2.30) are satisfied. We obtain Theorem 1.1 if we use $u, p$ with a change of scale (i.e., $u(x, t)$ is replaced by $a u(b x, c t)$ and $p(x, t)$ is replaced by $a^{2} p(b x, c t)$ for appropriate $\left.a, b, c\right)$ and a translation in the space coordinates.

\section{Section 3. The Basic Construction}

Throughout this section we fix $T, \theta, K_{1}, K_{2}, U_{1}, U_{2}, f_{1}, f_{2}, v_{1}, v_{2}$ such that $T>0$, $\theta>0$, and properties (3.1)-(3.7) are satisfied:

$K_{i} \subset U_{i} \subset P, K_{i}$ is compact, $U_{i}$ is open, $\operatorname{closure}\left(U_{i}\right) \subset P$,

$$
f_{i} \in C_{c}^{\infty}(P, R), \quad v_{i}=\left(v_{i 1}, v_{i 2}\right) \in C_{c}^{\infty}\left(P, R^{2}\right),
$$

closure $\left(U_{1}\right)$ and closure $\left(U_{2}\right)$ are disjoint compact sets, $\operatorname{spt}\left(v_{i}\right) \subset K_{i}$,

$$
\begin{gathered}
f_{i} \geqq 0, \quad f_{i}(x)=0 \quad \text { if } x \notin U_{i}, \quad f_{i}(x)>\left|v_{i}(x)\right| \quad \text { if } x \in U_{i}, \\
x_{2} \frac{\partial}{\partial x_{1}} v_{i 1}\left(x_{1}, x_{2}\right)+x_{2} \frac{\partial}{\partial x_{2}} v_{i 2}\left(x_{1}, x_{2}\right)+v_{i 2}\left(x_{1}, x_{2}\right)=0, \\
\left(f_{2}(x)\right)^{2}-T v_{2}(x) \cdot \nabla\left(p\left[v_{1}, f_{1}\right]-p\left[0, f_{1}\right]\right)(x)>\left|v_{2}(x)\right|^{2} \quad \text { if } x \in U_{2}, \\
L\left(f_{i}\right)(x) \geqq 0 \quad \text { if } x \notin K_{i}, \quad L\left(f_{i}\right)(x)>0 \quad \text { if } x \in U_{i} \sim K_{i} .
\end{gathered}
$$


Note that (3.1)-(3.4) imply that the functions $p\left[v_{1}, f_{1}\right]$ and $p\left[0, f_{1}\right]$ (which appear in (3.6)) are defined. We will see, in the course of the proof of Lemma 3.1, that the functions $p\left[v_{1}, h_{1, r}\right], p\left[0, h_{1, r}\right]$ appearing in (3.13) are also defined. Assumptions (3.1), (3.3), (3.6) imply that the quantity under the square root sign in (3.14) is nonnegative.

Lemma 3.1. There exist $\delta, g_{1}, g_{2}, h_{1}, h_{2}$ such that $\delta>0$ and (3.8)-(3.15) are satisfied:

$$
\begin{gathered}
g_{i} \in C_{c}^{\infty}(P, R), \quad h_{i}: P \times(-\delta, T+\delta) \rightarrow R \text { is } a C^{\infty} \text { function, } \\
\operatorname{spt}\left(g_{i}\right) \subset U_{i}, \quad \operatorname{spt}\left(v_{i}\right) \subset\left\{x: g_{i}(x)=1\right\}, \quad 0 \leqq g_{i}(x) \leqq 1 \quad \text { if } x \in P, \\
h_{i} \geqq 0, \quad h_{i}(x, t)>\left|v_{i}(x)\right| \quad \text { if } x \in \operatorname{spt}\left(g_{i}\right), \\
h_{i}(x, t)=f_{i}(x) \quad \text { if } x \notin \operatorname{spt}\left(g_{i}\right), \\
\left(h_{1}(x, t)\right)^{2}=\left(f_{1}(x)\right)^{2}-2 t \delta g_{1}(x), \\
\left(h_{2}(x, t)\right)^{2}=\left(f_{2}(x)\right)^{2}-2 t \delta g_{2}(x)-\int_{0}^{t} v_{2}(x) \cdot \nabla\left(p\left[v_{1}, h_{1, r}\right]-p\left[0, h_{1, r}\right]\right)(x) d r, \\
h_{2}(x, T)+\theta>\left(\left(f_{2}(x)\right)^{2}-T v_{2}(x) \cdot \nabla\left(p\left[v_{1}, f_{1}\right]-p\left[0, f_{1}\right]\right)(x)\right)^{1 / 2} \quad \text { if } x \in P, \\
L\left(h_{i, t}\right)(x) \geqq 0 \quad \text { if } g_{i}(x)<1 \quad\left(\text { where }_{i, t}(x)=h_{i}(x, t) \text { as in }(3.13)\right) .
\end{gathered}
$$

Proof. Assumption (3.1) allows us to find an open set $V_{i}$ with compact closure such that $K_{i} \subset V_{i}$ and closure $\left(V_{i}\right) \subset U_{i}$. Let $g_{i} \in C_{c}^{\infty}(P, R)$ satisfy $\operatorname{spt}\left(g_{i}\right) \subset U_{i}, g_{i}(x)=1$ if $x \in \operatorname{closure}\left(V_{i}\right)$, and

$$
0 \leqq g_{i}(x) \leqq 1 \quad \text { for all } x \in P .
$$

Let $W_{i}$ be an open set with compact closure such that $\operatorname{spt}\left(g_{i}\right) \subset W_{i}$ and closure $\left(W_{i}\right) \subset U_{i}$. Using (3.3), (3.4), (3.2) we get

$$
\begin{aligned}
\operatorname{spt}\left(v_{i}\right) & \subset K_{i} \subset V_{i} \subset \operatorname{closure}\left(V_{i}\right) \subset\left\{x: g_{i}(x)=1\right\} \subset \operatorname{spt}\left(g_{i}\right) \subset W_{i} \subset \operatorname{closure}\left(W_{i}\right) \\
& \subset U_{i} \subset\left\{x: f_{i}(x)>\left|v_{i}(x)\right|\right\} \subset \operatorname{spt}\left(f_{i}\right) \subset P .
\end{aligned}
$$

From (3.17) we conclude $f_{i}(x)>\left|v_{i}(x)\right|$ for all $x$ in the compact set closure $\left(W_{i}\right)$. From (3.7) and (3.17) we conclude $L\left(f_{i}\right)(x)>0$ for all $x$ in the compact set $\operatorname{closure}\left(W_{i}\right) \sim V_{i}$. Hence there exists $\varepsilon>0$ such that

$$
\begin{gathered}
f_{i}(x)>\left(\varepsilon^{2}+\left|v_{i}(x)\right|^{2}\right)^{1 / 2} \quad \text { if } x \in \operatorname{closure}\left(W_{i}\right), \\
L\left(f_{i}\right)(x)>\varepsilon \quad \text { if } x \in \operatorname{closure}\left(W_{i}\right) \sim V_{i} .
\end{gathered}
$$

If $i \in\{1,2\}, x \in P$ and $\delta \in R$ satisfy $2 \delta g_{i}(x) \leqq\left(f_{i}(x)\right)^{2}$ we define

$$
k_{i}(x, \delta)=\left(\left(f_{i}(x)\right)^{2}-2 \delta g_{i}(x)\right)^{1 / 2}, \quad k_{i, \delta}(x)=k_{i}(x, \delta) .
$$

If $x \in W_{i}$ and $\delta<\varepsilon^{2} / 2$ then (3.16) and (3.18) imply $2 \delta g_{i}(x)<\varepsilon^{2}<\left(f_{i}(x)\right)^{2}$. Hence $k_{i}$ is $C^{\infty}$ on $W_{i} \times\left(-\infty, \varepsilon^{2} / 2\right)$. The function $k_{i}$ is $C^{\infty}$ on $\left(P \sim \operatorname{spt}\left(g_{i}\right)\right) \times R$ because (3.4) implies $k_{i}(x, \delta)=\left(\left(f_{i}(x)\right)^{2}\right)^{1 / 2}=f_{i}(x)$ for $(x, \delta)$ in that set. All this and (3.17) (which implies $\operatorname{spt}\left(g_{i}\right) \subset W_{i}$ and $\left.\operatorname{spt}\left(g_{i}\right) \subset \operatorname{spt}\left(f_{i}\right)\right)$ yield 


$$
k_{i} \text { is } C^{\infty} \text { on } P \times\left(-\infty, \varepsilon^{2} / 2\right), \quad k_{i} \geqq 0, \quad \operatorname{spt}\left(k_{i, \delta}\right) \subset \operatorname{spt}\left(f_{i}\right) .
$$

Setting $L\left(k_{i}\right)(x, \delta)=L\left(k_{i, \delta}\right)(x)(\operatorname{see}(3.20))$, we conclude that $L\left(k_{i}\right)$ is a $C^{\infty}$ function on $P \times\left(-\infty, \varepsilon^{2} / 2\right)$. In particular, $L\left(k_{i}\right)$ is uniformly continuous on the compact set (closure $\left.\left(W_{i}\right) \sim V_{i}\right) \times\left[-\varepsilon^{2} / 4, \varepsilon^{2} / 4\right]$. Hence there exist $\delta_{0}>0$ such that $\delta_{0}<\varepsilon^{2} / 4$ and

$$
\left|L\left(k_{i}\right)(x, \delta)-L\left(k_{i}\right)(x, 0)\right|<\varepsilon / 2 \quad \text { if } x \in \operatorname{closure}\left(W_{i}\right) \sim V_{i} \text { and }|\delta| \leqq \delta_{0} .
$$

Combining this with $L\left(k_{i}\right)(x, 0)=L\left(f_{i}\right)(x)$ (see (3.4)) and (3.19) we obtain

$$
L\left(k_{i}\right)(x, \delta)>\varepsilon / 2 \quad \text { if } x \in \operatorname{closure}\left(W_{i}\right) \sim V_{i} \text { and }|\delta|<\delta_{0} .
$$

If $x \in P \sim \operatorname{closure}\left(W_{i}\right)$ then (3.17) yields $g_{i}(x)=0$ and $x \notin K_{i}$. In this case, (3.4) and (3.7) imply $L\left(k_{i}\right)(x, \delta)=L\left(f_{i}\right)(x) \geqq 0$. All this implies

$$
L\left(k_{i, \delta}\right)(x)=L\left(k_{i}\right)(x, \delta) \geqq 0 \quad \text { if } x \in P \sim V_{i} \quad \text { and } \quad|\delta|<\delta_{0} .
$$

If $x \in \operatorname{spt}\left(g_{i}\right)$ and $\delta<\varepsilon^{2} / 2$ then (3.16)-(3.18) imply $\left(f_{i}(x)\right)^{2}-2 \delta g_{i}(x)>\left(f_{i}(x)\right)^{2}-$ $\varepsilon^{2}>\left|v_{i}(x)\right|^{2}$. We obtain (see (3.20))

$$
k_{i, \delta}(x)>\left|v_{i}(x)\right| \geqq 0 \quad \text { if } x \in \operatorname{spt}\left(g_{i}\right) \text { and } \delta<\varepsilon^{2} / 2 .
$$

Assertions (3.17), (3.21) and (3.23) imply that $p\left[v_{1}, k_{1, \delta}\right]$ and $p\left[0, k_{1, \delta}\right]$ make sense for $\delta<\varepsilon^{2} / 2$. Hence, using the convention $\int_{a}^{b}=-\int_{b}^{a}$ and the notation

$$
H(x, t, \delta)=\left(f_{2}(x)\right)^{2}-2 \delta \operatorname{tg}_{2}(x)-\int_{0}^{t} v_{2}(x) \cdot \nabla\left(p\left[v_{1}, k_{1, r \delta}\right]-p\left[0, k_{1, r \delta}\right]\right)(x) d r
$$

we can say

$$
H \text { is a } C^{\infty} \text { function on } P \times(-2 T, 2 T) \times\left(-\varepsilon^{2} /(4 T), \varepsilon^{2} /(4 T)\right) .
$$

From (3.24), (3.20), (3.4) we obtain

$$
H(x, t, 0)=\left(f_{2}(x)\right)^{2}-t v_{2}(x) \cdot \nabla\left(p\left[v_{1}, f_{1}\right]-p\left[0, f_{1}\right]\right)(x) .
$$

If $x \in \operatorname{closure}\left(W_{2}\right)$ then (3.26), (3.17), (3.6) yield $H(x, 0,0)>\left|v_{2}(x)\right|^{2}$ and $H(x, T, 0)>\left|v_{2}(x)\right|^{2}$. The linearity of (3.26) in the variable $t$ implies $H(x, t, 0)>\left|v_{2}(x)\right|^{2}$ if $x \in \operatorname{closure}\left(W_{2}\right)$ and $t \in[0, T]$. Now the compactness of closure $\left(W_{2}\right) \times[0, T],(3.2)$ and (3.25) imply that there exists $\alpha>0$ such that $\alpha<T, \alpha<\varepsilon^{2} /(4 T)$ and

$$
H(x, t, \delta)>\left|v_{2}(x)\right|^{2} \quad \text { if } x \in \operatorname{closure}\left(W_{2}\right), \quad t \in[-\alpha, T+\alpha], \quad|\delta| \leqq \alpha .
$$

We will use the notation

$$
h(x, t, \delta)=(H(x, t, \delta))^{1 / 2} \quad \text { if } H(x, t, \delta) \geqq 0 .
$$

If $x \notin \operatorname{spt}\left(g_{2}\right)$ then the properties $x \notin \operatorname{spt}\left(v_{2}\right)$ (see (3.17)), (3.28), (3.24), (3.4) imply $h(x, t, \delta)=\left(\left(f_{2}(x)\right)^{2}\right)^{1 / 2}=f_{2}(x)$. Hence (3.25) implies that $h$ is $C^{\infty}$ on the set

$$
\left(P \sim \operatorname{spt}\left(g_{2}\right)\right) \times(-2 T, 2 T) \times\left(-\varepsilon^{2} /(4 T), \varepsilon^{2} /(4 T)\right) .
$$

From (3.25), (3.27), (3.28) we obtain that $h$ is $C^{\infty}$ on the set $W_{2} \times(-\alpha, T+\alpha) \times$ $(-\alpha, \alpha)$. All this, (3.17), $\alpha<T$ and $\alpha<\varepsilon^{2} /(4 T)$ imply

$$
h \geqq 0, \quad h \text { is } C^{\infty} \text { on } P \times(-\alpha, T+\alpha) \times(-\alpha, \alpha) .
$$


Furthermore, (3.27), (3.28) and (3.17) yield

$$
h(x, t, \delta)>\left|v_{2}(x)\right| \quad \text { if } x \in \operatorname{spt}\left(g_{2}\right), \quad t \in(-\alpha, T+\alpha), \quad|\delta|<\alpha .
$$

Using $\operatorname{spt}\left(v_{2}\right) \subset \operatorname{spt}\left(\mathrm{g}_{2}\right) \subset \operatorname{spt}\left(f_{2}\right)$ (see (3.17)), (3.24), (3.28), (3.4) we find

$$
h(x, t, \delta)=0 \quad \text { if } x \notin \operatorname{spt}\left(f_{2}\right), \quad h(x, t, \delta)=f_{2}(x) \quad \text { if } x \notin \operatorname{spt}\left(g_{2}\right) .
$$

Recall that we fixed $\theta>0$ at the beginning of this section. Now we use (3.29) and (3.2) to fix $\delta_{1}>0$ such that $\left(T+\delta_{1}\right) \delta_{1}<\delta_{0}<\varepsilon^{2} / 4, \delta_{1}<\alpha$ and the inequality $\left|h\left(x, T, \delta_{1}\right)-h(x, T, 0)\right|<\theta$ holds for all $x \in \operatorname{spt}\left(f_{2}\right)$. From (3.31) we obtain that $\left|h\left(x, T, \delta_{1}\right)-h(x, T, 0)\right|<\theta$ holds for all $x \in P$. This implies (see (3.26), (3.28), (3.29))

$$
h\left(x, T, \delta_{1}\right)+\theta>\left(\left(f_{2}(x)\right)^{2}-T v_{2}(x) \cdot \nabla\left(p\left[v_{1}, f_{1}\right]-p\left[0, f_{1}\right]\right)(x)\right)^{1 / 2}
$$

for all $x \in P$. We define $h_{i}: P \times\left(-\delta_{1}, T+\delta_{1}\right) \rightarrow R$ and $h_{i, t}$ by (see (3.21))

$$
h_{1}(x, t)=k_{1}\left(x, t \delta_{1}\right), \quad h_{2}(x, t)=h\left(x, t, \delta_{1}\right), \quad h_{i, t}(x)=h_{i}(x, t) .
$$

If $(x, t) \in P \times\left(-\delta_{1}, T+\delta_{1}\right)$ satisfies $g_{2}(x)<1$ then (3.17) implies $v_{2}(x)=0$. Therefore, (3.28), (3.24), (3.20) yield

$$
h_{2}(x, t)=h\left(x, t, \delta_{1}\right)=\left(\left(f_{2}(x)\right)^{2}-2 \delta_{1} \operatorname{tg}_{2}(x)\right)^{1 / 2}=k_{2}\left(x, t \delta_{1}\right)
$$

in this case. The definition of $h_{1}$ and the above imply

$$
\text { if } g_{i}(x)<1 \quad \text { and } \quad-\delta_{1}<t<T+\delta_{1} \quad \text { then } \quad h_{i}(x, t)=k_{i}\left(x, t \delta_{1}\right) .
$$

The number $\delta$ in the statement of the lemma will be $\delta_{1}$. From the definition of $g_{i}, 0<\delta_{1}<\alpha,\left(T+\delta_{1}\right) \delta_{1}<\varepsilon^{2} / 2$, (3.21), (3.29) we conclude (3.8). Assertion (3.9) is a consequence of (3.16), (3.17). Properties (3.23), (3.20), $\left(T+\delta_{1}\right) \delta_{1}<\varepsilon^{2} / 2$, (3.29), (3.30), $0<\delta_{1}<\alpha$ imply (3.10). Assertions (3.4), (3.20), (3.31) imply (3.11). We obtain (3.12)-(3.14) from (3.20), (3.24), (3.28) and (3.32). Finally, (3.15) follows from (3.22), (3.33), (3.17) and $\left(T+\delta_{1}\right) \delta_{1}<\delta_{0}$.

Lemma 3.2. Let $\delta, g_{i}, h_{i}$ be as in Lemma 3.1. Then there exist $d, N, J^{z}$ for $z \in\{1,2,3\}$, and $q_{i}^{z}$ for $i \in\{1,2\}, z \in\{1,2,3\}$ such that (3.34)-(3.41) are satisfied:

$$
N \text { is a positive integer, } d=T /(4 N) \text {, }
$$

$J^{z}$ is an open subset of $(-\delta, T+\delta), q_{i}^{z}: P \times J^{z} \rightarrow R$ is $C^{\infty}$,

$$
[4 n d, 4 n d+d] \subset J^{1},[4 n d+d, 4 n d+2 d] \subset J^{2},
$$

$$
[4 n d+2 d, 4 n d+4 d] \subset J^{3} \text { if } n \in\{0,1, \ldots, N-1\} \text {, }
$$

$$
\begin{aligned}
q_{i}^{1}(x, 4 n d+d) & =q_{i}^{2}(x, 4 n d+d), q_{i}^{2}(x, 4 n d+2 d)=q_{i}^{3}(x, 4 n d+d), \\
q_{i}^{3}(x, 4 n d+4 d) & =q_{i}^{1}(x, 4 n d+4 d) \quad \text { if } n \in\{0,1, \ldots, N-1\},
\end{aligned}
$$

$$
\begin{gathered}
q_{i}^{z} \geqq 0, \quad q_{i}^{z}(x, t)=h_{i}(x, t) \quad \text { if } x \notin \operatorname{spt}\left(v_{i}\right), \\
q_{i}^{z}(x, t)>\left|v_{i}(x)\right| \quad \text { if } x \in \operatorname{spt}\left(v_{i}\right), \\
q_{i}^{1}(x, 0)=h_{i}(x, 0), \quad q_{i}^{3}(x, T)=h_{i}(x, T),
\end{gathered}
$$




$$
\frac{\partial}{\partial t} 2^{-1}\left(q_{i}^{z}(x, t)\right)^{2} \leqq \delta / 2-\delta g_{i}(x)-S_{i}^{z} v_{i}^{z}(x) \cdot \nabla\left(2^{-1}\left(q_{i, t}^{z}\right)^{2}+p\left[v_{1}^{z}, q_{1, t}^{z}\right]+p\left[v_{2}^{z}, q_{2, t}^{z}\right]\right)(x),
$$

$$
\text { where } \begin{aligned}
S_{1}^{1} & =S_{2}^{1}=S_{2}^{2}=S_{1}^{3}=1, \quad S_{1}^{2}=S_{2}^{3}=-1, \quad v_{1}^{1}=v_{1}^{2} \\
& =v_{1}, \quad v_{1}^{3}=0, \quad v_{2}^{z}=v_{2}, \quad \text { and } \quad q_{i, t}^{z}(x)=q_{i}^{z}(x, t) .
\end{aligned}
$$

Proof. If $i \in\{1,2\}$ and $j \in\{1,2\}$ we define $w_{i}^{j}: P \rightarrow R^{2}$ as follows:

$$
w_{i}^{j}=v_{1} \quad \text { if }(i, j) \neq(2,2), \quad w_{2}^{2}=0 .
$$

From (3.9), (3.4) we obtain

$$
\operatorname{spt}\left(v_{i}\right) \subset \operatorname{spt}\left(g_{i}\right) \subset \operatorname{spt}\left(f_{i}\right) .
$$

Recall the notation $h_{i, t}(x)=h_{i}(x, t)$ introduced in (3.13). Properties (3.8), (3.10), (3.42), (3.43), (3.2) imply that $p\left[w_{i}^{j}, h_{1, t}\right]$ and $p\left[v_{2}, h_{2, t}\right]$ make sense for $t \in(-\delta, T+\delta)$. This fact, (3.8), and the convention $\int_{a}^{b}=-\int_{b}^{a}$ allow us to use the notation

$$
\begin{aligned}
M_{i}^{j}(x, t, s)= & \left(h_{i}(x, t)\right)^{2}-2 s \delta g_{i}(x)+(-1)^{j} \int_{0}^{2 s} v_{i}(x) \cdot \nabla\left(2^{-1}\left(h_{i, t+r}\right)^{2}\right. \\
& \left.+p\left[w_{i}^{j}, h_{1, t+r}\right]+p\left[v_{2}, h_{2, t+r}\right]\right)(x) d r
\end{aligned}
$$

if $\{i, j\} \subset\{1,2\}, x \in P,-\delta / 3<t<T+\delta / 3$ and $|s|<\delta / 3$. We have

$$
M_{i}^{j} \text { is a } C^{\infty} \text { function on } P \times(-\delta / 3, T+\delta / 3) \times(-\delta / 3, \delta / 3) .
$$

We will also use the notation

$$
m_{i}^{j}(x, t, s)=\left(M_{i}^{j}(x, t, s)\right)^{1 / 2} \quad \text { if }(x, t, s) \text { satisfies } M_{i}^{j}(x, t, s) \geqq 0 .
$$

If $(x, t)$ is in the compact set $\operatorname{spt}\left(g_{i}\right) \times[0, T]$ then (3.44), (3.45), (3.10) yield $M_{i}^{j}(x, t, 0)=\left(h_{i}(x, t)\right)^{2}>\left|v_{i}(x)\right|^{2}$. Hence (3.45), (3.2) imply that there exist an open set $E_{i} \subset P$ and a number $\beta>0$ such that $\operatorname{spt}\left(g_{i}\right) \subset E_{i}, \beta<\delta / 3$ and

$$
M_{i}^{j}(x, t, s)>\left|v_{i}(x)\right|^{2} \quad \text { if }(x, t, s) \in E_{i} \times(-\beta, T+\beta) \times(-\beta, \beta) .
$$

Using (3.45)-(3.47) we conclude

$$
m_{i}^{j} \text { is } C^{\infty} \text { on } E_{i} \times(-\beta, T+\beta) \times(-\beta, \beta) .
$$

If $x \notin \operatorname{spt}\left(g_{i}\right)$ then (3.43) and (3.44) yield $M_{i}^{j}(x, t, s)=\left(h_{i}(x, t)\right)^{2}$. Combining this with (3.45), (3.46), $h_{i} \geqq 0$ (see (3.10)) and $\beta<\delta / 3$ we find

$$
m_{i}^{j}(x, t, s)=h_{i}(x, t) \quad \text { if }(x, t, s) \in\left(P \sim \operatorname{spt}\left(g_{i}\right)\right) \times(-\beta, T+\beta) \times(-\beta, \beta),
$$

and hence (3.8) implies that $m_{i}^{j}$ is $C^{\infty}$ on the set mentioned in (3.49). This last assertion, (3.48), and $\operatorname{spt}\left(g_{i}\right) \subset E_{i}$ imply

$$
m_{i}^{j} \text { is } C^{\infty} \text { on } P \times(-\beta, T+\beta) \times(-\beta, \beta) .
$$

Using (3.46), (3.47) and $\operatorname{spt}\left(g_{i}\right) \subset E_{i}$ we find

$$
m_{i}^{j}(x, t, s)>\left|v_{i}(x)\right| \quad \text { if }(x, t, s) \in \operatorname{spt}\left(g_{i}\right) \times(-\beta, T+\beta) \times(-\beta, \beta) .
$$


For future reference, we use (3.44), (3.46), (3.50) to write

$$
\begin{aligned}
\left(m_{i}^{j}(x, t, s)\right)^{2}= & \left(h_{i}(x, t)\right)^{2}-2 s \delta g_{i}(x) \\
& +(-1)^{j} \int_{0}^{2 s} v_{i}(x) \cdot \nabla\left(2^{-1}\left(h_{i, t+r}\right)^{2}+p\left[w_{i}^{j}, h_{1, t+r}\right]\right. \\
& \left.+p\left[v_{2}, h_{2, t+r}\right]\right)(x) d r \\
& \text { if }(x, t, s) \in P \times(-\beta, T+\beta) \times(-\beta, \beta) .
\end{aligned}
$$

We will use the notation

$$
m_{i, t, s}^{j}(x)=m_{i}^{j}(x, t, s) .
$$

Properties (3.49), (3.11), $\operatorname{spt}\left(g_{i}\right) \subset \operatorname{spt}\left(f_{i}\right)$ (which follows from (3.4) and (3.9)) and (3.46) imply

$$
\operatorname{spt}\left(m_{i, t, s}^{j}\right) \subset \operatorname{spt}\left(f_{i}\right), \quad m_{i, t, s}^{j} \geqq 0 \quad \text { if }(t, s) \in(-\beta, T+\beta) \times(-\beta, \beta) .
$$

Now (3.53), (3.51), (3.43), (3.54), (3.2) imply that $p\left[v_{i}, m_{i, t, s}^{j}\right]$ and $p\left[0, m_{i, t, s}^{j}\right]$ make sense if $(t, s) \in(-\beta, T+\beta) \times(-\beta, \beta)$. We define

$$
\begin{aligned}
& F_{i}^{j, 0}(x, t, s)=v_{i}(x) \cdot \nabla\left(2^{-1}\left(m_{i, t, s}^{j}\right)^{2}\right)(x), \\
& F_{i}^{j, k}(x, t, s)=v_{i}(x) \cdot \nabla\left(p\left[v_{k}, m_{k, t, s}^{j}\right]\right)(x) \text { if } k=1,2, \\
& F_{2}^{2,3}(x, t, s)=v_{2}(x) \cdot \nabla\left(p\left[0, m_{1, t, s}^{2}\right]\right)(x)
\end{aligned}
$$

for $(x, t, s) \in P \times(-\beta, T+\beta) \times(-\beta, \beta)$. We use (3.2), (3.50) to choose $d>0$ such that $8 d<\beta / 2, N=T /(4 d)$ is an integer and

$$
\begin{gathered}
\left|F_{i}^{j, k}(x, t, s)-F_{i}^{j, k}\left(x, t^{\prime}, 0\right)\right|<\delta / 6 \\
\text { if }\left\{t, t^{\prime}\right\} \subset[-\beta / 2, T+\beta / 2], \quad\left|t-t^{\prime}\right|<8 d, \quad|s|<8 d .
\end{gathered}
$$

For $n \in\{0,1, \ldots, N-1\}$ we set

$$
\begin{aligned}
& J_{n}^{1}=(4 n d-d / 3,4 n d+d+d / 3), \\
& J_{n}^{2}=(4 n d+d-d / 3,4 n d+2 d+d / 3), \\
& J_{n}^{3}=(4 n d+2 d-d / 3,4 n d+4 d+d / 3), \\
& J^{z}=\bigcup_{n=0}^{N-1} J_{n}^{z} \quad \text { if } z \in\{1,2,3\} .
\end{aligned}
$$

If $z$ is fixed then the intervals $J_{0}^{z}, J_{1}^{z}, \ldots, J_{N-1}^{z}$ are disjoint. Hence the properties $N=T /(4 d), 8 d<\beta / 2, \beta<\delta / 3,(3.8)$ and (3.50) allow us to define $q_{i}^{z}: P \times J^{z} \rightarrow R$ as follows:

$$
\begin{aligned}
& \text { If } t \in J_{n}^{1} \text { then } q_{1}^{1}(x, t)=m_{1}^{1}(x, 4 n d, t-4 n d), \\
& \text { If } t \in J_{n}^{2} \text { then } q_{1}^{2}(x, t)=m_{1}^{2}(x, 4 n d+2 d, t-(4 n d+2 d)), \\
& \text { If } t \in J_{n}^{3} \text { then } q_{1}^{3}(x, t)=h_{1}(x, t), \\
& \text { If } t \in J_{n}^{1} \text { then } q_{2}^{1}(x, t)=m_{2}^{1}(x, 4 n d, t-4 n d),
\end{aligned}
$$




$$
\begin{aligned}
& \text { If } t \in J_{n}^{2} \text { then } q_{2}^{2}(x, t)=m_{2}^{1}(x, 4 n d, t-4 n d), \\
& \text { If } t \in J_{n}^{3} \text { then } q_{2}^{3}(x, t)=m_{2}^{2}(x, 4 n d+4 d, t-(4 n d+4 d)) .
\end{aligned}
$$

Note that, in (3.58), $m_{i}^{j}$ is evaluated only at points in $P \times(-\beta / 2, T+\beta / 2) \times$ $(-\beta / 2, \beta / 2)$. Using (3.46), (3.10) we find

$$
q_{i}^{z} \geqq 0 .
$$

If $x \notin \operatorname{spt}\left(v_{i}\right)$ then (3.12), (3.13) imply that the identity in (3.52) reduces to

$$
\left(m_{i}^{j}(x, t, s)\right)^{2}=\left(h_{i}(x, t)\right)^{2}-2 s \delta g_{i}(x)=\left(f_{i}(x)\right)^{2}-2 t \delta g_{i}(x)-2 s \delta g_{i}(x)=\left(h_{i}(x, t+s)\right)^{2} .
$$

The above and (3.58) yield $\left(q_{i}^{z}(x, t)\right)^{2}=\left(h_{i}(x, t)\right)^{2}$ if $x \notin \operatorname{spt}\left(v_{i}\right)$. Now (3.10) and (3.59) imply

$$
q_{i}^{z}(x, t)=h_{i}(x, t) \quad \text { if } x \in P \sim \operatorname{spt}\left(v_{i}\right) \text { and } \quad t \in J^{z} .
$$

From (3.58), (3.51) and (3.10) we conclude

$$
q_{i}^{z}(x, t)>\left|v_{i}(x)\right| \text { if } x \in \operatorname{spt}\left(g_{i}\right) \text { and } t \in J^{z} .
$$

Properties (3.58), (3.57), (3.52), (3.42), (3.12) and the argument

$$
\int_{0}^{2 d} F(r) d r=\int_{-2 d}^{0} F(2 d+r) d r=-\int_{0}^{-2 d} F(2 d+r) d r
$$

which is valid for an arbitrary $F$, yield

$$
\begin{aligned}
\left(q_{1}^{1}(x, 4 n d+d)\right)^{2}= & \left(m_{1}^{1}(x, 4 n d, d)\right)^{2}=\left(h_{1}(x, 4 n d)\right)^{2}-2 d \delta g_{1}(x) \\
& -\int_{0}^{2 d} v_{1}(x) \cdot \nabla\left(2^{-1}\left(h_{1,4 n d+r}\right)^{2}+\sum_{k=1}^{2} p\left[v_{k}, h_{k, 4 n d+r}\right]\right)(x) d r \\
= & \left(h_{1}(x, 4 n d+2 d)\right)^{2}+2 d \delta g_{1}(x) \\
& -\int_{0}^{2 d} v_{1}(x) \cdot \nabla\left(2^{-1}\left(h_{1,4 n d+r}\right)^{2}+\sum_{k=1}^{2} p\left[v_{k}, h_{k, 4 n d+r}\right]\right)(x) d r \\
= & \left(h_{1}(x, 4 n d+2 d)\right)^{2}+2 d \delta g_{1}(x) \\
& +\int_{0}^{-2 d} v_{1}(x) \cdot \nabla\left(2^{-1}\left(h_{1,4 n d+2 d+r}\right)^{2}+\sum_{k=1}^{2} p\left[v_{k}, h_{k, 4 n d+2 d+r}\right]\right)(x) d r \\
= & \left(m_{1}^{2}(x, 4 n d+2 d,-d)\right)^{2}=\left(q_{1}^{2}(x, 4 n d+d)\right)^{2} .
\end{aligned}
$$

From (3.13) we obtain

$$
\begin{aligned}
& \left(h_{2}(x, 4 n d+4 d)\right)^{2}-\left(h_{2}(x, 4 n d)\right)^{2} \\
& =-8 d \delta g_{2}(x)-\int_{4 n d}^{4 n d+4 d} v_{2}(x) \cdot \nabla\left(p\left[v_{1}, h_{1, r}\right]-p\left[0, h_{1, r}\right]\right)(x) d r \\
& =-8 d \delta g_{2}(x)-\int_{0}^{4 d} v_{2}(x) \cdot \nabla\left(p\left[v_{1}, h_{1,4 n d+r}\right]-p\left[0, h_{1,4 n d+r}\right]\right)(x) d r
\end{aligned}
$$


Using (3.58), (3.57), (3.52), (3.42) and the argument

$$
\int_{0}^{-4 d} F(r) d r=-\int_{-4 d}^{0} F(r) d r=-\int_{0}^{4 d} F(r-4 d) d r,
$$

for arbitrary $F$, we find

$$
\begin{aligned}
\left(q_{2}^{3}(x, 4 n d+2 d)\right)^{2}-\left(q_{2}^{2}(x, 4 n d+2 d)\right)^{2} & \\
= & \left(m_{2}^{2}(x, 4 n d+4 d,-2 d)\right)^{2}-\left(m_{2}^{1}(x, 4 n d, 2 d)\right)^{2} \\
= & \left(h_{2}(x, 4 n d+4 d)\right)^{2}+4 d \delta g_{2}(x)+\int_{0}^{-4 d} v_{2}(x) \cdot \nabla\left(2^{-1}\left(h_{2,4 n d+4 d+r}\right)^{2}\right. \\
& \left.+p\left[0, h_{1,4 n d+4 d+r}\right]+p\left[v_{2}, h_{2,4 n d+4 d+r}\right]\right)(x) d r-\left(h_{2}(x, 4 n d)\right)^{2}+4 d \delta g_{2}(x) \\
& \quad+\int_{0}^{4 d} v_{2}(x) \cdot \nabla\left(2^{-1}\left(h_{2,4 n d+r}\right)^{2}+p\left[v_{1}, h_{1,4 n d+r}\right]+p\left[v_{2}, h_{2,4 n d+r}\right]\right)(x) d r \\
= & \left(h_{2}(x, 4 n d+4 d)\right)^{2}-\left(h_{2}(x, 4 n d)\right)^{2}+8 d \delta g_{2}(x) \\
& \quad+\int_{0}^{4 d} v_{2}(x) \cdot \nabla\left(p\left[v_{1}, h_{1,4 n d+r}\right]-p\left[0, h_{1,4 n d+r}\right]\right)(x) d r
\end{aligned}
$$

The above and (3.63) yield

$$
\left(q_{2}^{2}(x, 4 n d+2 d)\right)^{2}=\left(q_{2}^{3}(x, 4 n d+2 d)\right)^{2} .
$$

Using (3.58), (3.57), (3.52) we obtain

$$
\begin{aligned}
\left(q_{1}^{2}(x, 4 n d+2 d)\right)^{2} & =\left(m_{1}^{2}(x, 4 n d+2 d, 0)\right)^{2}=\left(h_{1}(x, 4 n d+2 d)\right)^{2} \\
& =\left(q_{1}^{3}(x, 4 n d+2 d)\right)^{2} \\
\left(q_{1}^{3}(x, 4 n d+4 d)\right)^{2} & =\left(h_{1}(x, 4 n d+4 d)\right)^{2}=\left(m_{1}^{1}(x, 4 n d+4 d, 0)\right)^{2} \\
& =\left(m_{1}^{1}(x, 4(n+1) d, 0)\right)^{2}=\left(q_{1}^{1}(x, 4(n+1) d)\right)^{2} \\
q_{2}^{1}(x, 4 n d+d) & =m_{2}^{1}(x, 4 n d, d)=q_{2}^{2}(x, 4 n d+d), \\
\left(q_{2}^{3}(x, 4 n d+4 d)\right)^{2} & =\left(m_{2}^{2}(x, 4 n d+4 d, 0)\right)^{2}=\left(h_{2}(x, 4 n d+4 d)\right)^{2} \\
& =\left(m_{2}^{1}(x, 4 n d+4 d, 0)\right)^{2}=\left(m_{2}^{1}(x, 4(n+1) d, 0)\right)^{2} \\
& =\left(q_{2}^{1}(x, 4(n+1) d)\right)^{2} .
\end{aligned}
$$

Our construction yields (3.34)-(3.36). Assertion (3.37) is a consequence of (3.59), (3.62), (3.64)-(3.68). Properties (3.59), (3.60) yield (3.38). From (3.61) and (3.43) we obtain (3.39). Using (3.58), (3.57), $N=T /(4 d)$, (3.52), (3.59), (3.10) we conclude (3.40). The proof of the lemma will be completed by showing (3.41).

From (3.52), (3.53)-(3.55), (3.10) we get

$$
\begin{aligned}
& F_{i}^{j, 0}(x, t, 0)=v_{i}(x) \cdot \nabla\left(2^{-1}\left(h_{i, t}\right)^{2}\right)(x), \\
& F_{i}^{j, k}(x, t, 0)=v_{i}(x) \cdot \nabla\left(p\left[v_{k}, h_{k, t}\right]\right)(x) \text { if } k=1,2, \\
& F_{2}^{2,3}(x, t, 0)=v_{2}(x) \cdot \nabla\left(p\left[0, h_{1, t}\right]\right)(x) .
\end{aligned}
$$


The identity (3.52) gives us

$$
\begin{aligned}
\frac{\partial}{\partial s} 2^{-1}\left(m_{i}^{j}(x, t, s)\right)^{2}= & -\delta g_{i}(x)+(-1)^{j} v_{i}(x) \cdot \nabla\left(2^{-1}\left(h_{i, t+2 s}\right)^{2}+p\left[w_{i}^{j}, h_{1, t+2 s}\right]\right. \\
& \left.+p\left[v_{2}, h_{2, t+2 s}\right]\right)(x)
\end{aligned}
$$

We will use the notation $q_{i, t}^{z}(x)=q_{i}^{z}(x, t)$. Assertions (3.59)-(3.61), (3.11), (3.43), (3.2) imply that $p\left[v_{i}, q_{i, t}^{z}\right]$ and $p\left[0, q_{i, t}^{z}\right]$ make sense. If $t \in J_{n}^{1}$ then (3.58), (3.53), (3.55) imply

$$
\begin{aligned}
& v_{i}(x) \cdot \nabla\left(2^{-1}\left(q_{i, t}^{1}\right)^{2}\right)(x)=F_{i}^{1,0}(x, 4 n d, t-4 n d), \\
& v_{i}(x) \cdot \nabla\left(p\left[v_{k}, q_{k, t}^{1}\right]\right)(x)=F_{i}^{1, k}(x, 4 n d, t-4 n d) \quad \text { if } k=1,2 .
\end{aligned}
$$

The above, (3.69), (3.70), (3.58) and (3.42) yield the following for $t \in J_{n}^{1}$ :

$$
\begin{aligned}
- & \delta g_{i}(x)+\sum_{k=0}^{2}\left(F_{i}^{1, k}(x, 4 n d, t-4 n d)-F_{i}^{1, k}(x, 2 t-4 n d, 0)\right) \\
& -v_{i}(x) \cdot \nabla\left(2^{-1}\left(q_{i, t}^{1}\right)^{2}+p\left[v_{1}, q_{1, t}^{1}\right]+p\left[v_{2}, q_{2, t}^{1}\right]\right)(x) \\
= & -\delta g_{i}(x)-\sum_{k=0}^{2} F_{i}^{1, k}(x, 2 t-4 n d, 0) \\
= & -\delta g_{i}(x)-v_{i}(x) \cdot \nabla\left(2^{-1}\left(h_{i, 2 t-4 n d}\right)^{2}+\sum_{k=1}^{2} p\left[v_{k}, h_{k, 2 t-4 n d}\right]\right)(x) \\
= & \frac{\partial}{\partial t} 2^{-1}\left(q_{i}^{1}(x, t)\right)^{2} .
\end{aligned}
$$

The above, (3.56) and the definition of $J_{n}^{1}$ imply $\frac{\partial}{\partial t} 2^{-1}\left(q_{i}^{1}(x, t)\right)^{2} \leqq \delta / 2-\delta g_{i}(x)-v_{i}(x) \cdot \nabla\left(2^{-1}\left(q_{i, t}^{1}\right)^{2}+p\left[v_{1}, q_{1, t}^{1}\right]+p\left[v_{2}, q_{2, t}^{1}\right]\right)(x)$.

If $t \in J_{n}^{2}$ then (3.58), (3.53), (3.55) imply

$$
\begin{aligned}
& v_{1}(x) \cdot \nabla\left(2^{-1}\left(q_{1, t}^{2}\right)^{2}\right)(x)=F_{1}^{2,0}(x, 4 n d+2 d, t-(4 n d+2 d)), \\
& v_{1}(x) \cdot \nabla\left(p\left[v_{1}, q_{1, t}^{2}\right]\right)(x)=F_{1}^{2,1}(x, 4 n d+2 d, t-(4 n d+2 d)), \\
& v_{1}(x) \cdot \nabla\left(p\left[v_{2}, q_{2, t}^{2}\right]\right)(x)=F_{1}^{1,2}(x, 4 n d, t-4 n d) .
\end{aligned}
$$

The above, (3.69), (3.70), (3.58) and (3.42) yield the following for $t \in J_{n}^{2}$ :

$$
\begin{aligned}
- & \delta g_{1}(x)+\sum_{k=0}^{1}\left(F_{1}^{2, k}(x, 2 t-4 n d-2 d, 0)-F_{1}^{2, k}(x, 4 n d+2 d, t-4 n d-2 d)\right) \\
& +\left(F_{1}^{1,2}(x, 2 t-4 n d-2 d, 0)-F_{1}^{1,2}(x, 4 n d, t-4 n d)\right) \\
& +v_{1}(x) \cdot \nabla\left(2^{-1}\left(q_{1, t}^{2}\right)^{2}+p\left[v_{1}, q_{1, t}^{2}\right]+p\left[v_{2}, q_{2, t}^{2}\right]\right)(x) \\
=- & \delta g_{1}(x)+\sum_{k=0}^{1} F_{1}^{2, k}(x, 2 t-4 n d-2 d, 0)+F_{1}^{1,2}(x, 2 t-4 n d-2 d, 0)
\end{aligned}
$$




$$
\begin{aligned}
& =-\delta g_{1}(x)+v_{1}(x) \cdot \nabla\left(2^{-1}\left(h_{1,2 t-4 n d-2 d}\right)^{2}+\sum_{k=1}^{2} p\left[v_{k}, h_{k, 2 t-4 n d-2 d}\right]\right)(x) \\
& =\frac{\partial}{\partial t} 2^{-1}\left(q_{1}^{2}(x, t)\right)^{2} .
\end{aligned}
$$

The above, (3.56) and the definition of $J_{n}^{2}$ imply

$\frac{\partial}{\partial t} 2^{-1}\left(q_{1}^{2}(x, t)\right)^{2} \leqq \delta / 2-\delta g_{1}(x)+v_{1}(x) \cdot \nabla\left(2^{-1}\left(q_{1, t}^{2}\right)^{2}+p\left[v_{1}, q_{1, t}^{2}\right]+p\left[v_{2}, q_{2, t}^{2}\right]\right)(x)$.

If $t \in J_{n}^{2}$ then (3.58), (3.53), (3.55) imply

$$
\begin{aligned}
& v_{2}(x) \cdot \nabla\left(2^{-1}\left(q_{2, t}^{2}\right)^{2}\right)(x)=F_{2}^{1,0}(x, 4 n d, t-4 n d), \\
& v_{2}(x) \cdot \nabla\left(p\left[v_{1}, q_{1, t}^{2}\right]\right)(x)=F_{2}^{2,1}(x, 4 n d+2 d, t-(4 n d+2 d)), \\
& v_{2}(x) \cdot \nabla\left(p\left[v_{2}, q_{2, t}^{2}\right]\right)(x)=F_{2}^{1,2}(x, 4 n d, t-4 n d) .
\end{aligned}
$$

The above, (3.69), (3.70), (3.58) and (3.42) yield the following for $t \in J_{n}^{2}$ :

$$
\begin{aligned}
&-\delta g_{2}(x)+\left(F_{2}^{1,0}(x, 4 n d, t-4 n d)-F_{2}^{1,0}(x, 2 t-4 n d, 0)\right) \\
&+\left(F_{2}^{2,1}(x, 4 n d+2 d, t-4 n d-2 d)-F_{2}^{2,1}(x, 2 t-4 n d, 0)\right) \\
&+\left(F_{2}^{1,2}(x, 4 n d, t-4 n d)-F_{2}^{1,2}(x, 2 t-4 n d, 0)\right) \\
&-v_{2}(x) \cdot \nabla\left(2^{-1}\left(q_{2, t}^{2}\right)^{2}+p\left[v_{1}, q_{1, t}^{2}\right]+p\left[v_{2}, q_{2, t}^{2}\right]\right)(x) \\
&=- \delta g_{2}(x)-F_{2}^{1,0}(x, 2 t-4 n d, 0)-F_{2}^{2,1}(x, 2 t-4 n d, 0) \\
& \quad-F_{2}^{1,2}(x, 2 t-4 n d, 0) \\
&=- \delta g_{2}(x)-v_{2}(x) \cdot \nabla\left(2^{-1}\left(h_{2,2 t-4 n d}\right)^{2}+\sum_{k=1}^{2} p\left[v_{k}, h_{k, 2 t-4 n d}\right]\right)(x) \\
&=\frac{\partial}{\partial t} 2^{-1}\left(q_{2}^{2}(x, t)\right)^{2} .
\end{aligned}
$$

The above, (3.56) and the definition of $J_{n}^{2}$ imply

$$
\frac{\partial}{\partial t} 2^{-1}\left(q_{2}^{2}(x, t)\right)^{2} \leqq \delta / 2-\delta g_{2}(x)-v_{2}(x) \cdot \nabla\left(2^{-1}\left(q_{2, t}^{2}\right)^{2}+p\left[v_{1}, q_{1, t}^{2}\right]+p\left[v_{2}, q_{2, t}^{2}\right]\right)(x) .
$$

Finally, if $t \in J_{n}^{3}$ then (3.58), (3.53), (3.55), (3.69) imply

$$
\begin{aligned}
v_{2}(x) \cdot \nabla\left(2^{-1}\left(q_{2, t}^{3}\right)^{2}\right)(x) & =F_{2}^{2,0}(x, 4 n d+4 d, t-(4 n d+4 d)), \\
v_{2}(x) \cdot \nabla\left(p\left[0, q_{1, t}^{3}\right]\right)(x) & =F_{2}^{2,3}(x, t, 0), \\
v_{2}(x) \cdot \nabla\left(p\left[v_{2}, q_{2, t}^{3}\right]\right)(x) & =F_{2}^{2,2}(x, 4 n d+4 d, t-(4 n d+4 d)) .
\end{aligned}
$$


The above, (3.69), (3.70), (3.58) and (3.42) yield the following for $t \in J_{n}^{3}$ :

$$
\begin{aligned}
- & \delta g_{2}(x)+\left(F_{2}^{2,0}(x, 2 t-4 n d-4 d, 0)-F_{2}^{2,0}(x, 4 n d+4 d, t-(4 n d+4 d))\right) \\
& +\left(F_{2}^{2,3}(x, 2 t-4 n d-4 d, 0)-F_{2}^{2,3}(x, t, 0)\right) \\
& +\left(F_{2}^{2,2}(x, 2 t-4 n d-4 d, 0)-F_{2}^{2,2}(x, 4 n d+4 d, t-(4 n d+4 d))\right) \\
& +v_{2}(x) \cdot \nabla\left(2^{-1}\left(q_{2, t}^{3}\right)^{2}+p\left[0, q_{1, t}^{3}\right]+p\left[v_{2}, q_{2, t}^{3}\right]\right)(x) \\
= & -\delta g_{2}(x)+F_{2}^{2,0}(x, 2 t-4 n d-4 d, 0)+F_{2}^{2,3}(x, 2 t-4 n d-4 d, 0) \\
& +F_{2}^{2,2}(x, 2 t-4 n d-4 d, 0) \\
= & -\delta g_{2}(x)+v_{2}(x) \cdot \nabla\left(2^{-1}\left(h_{2,2 t-4 n d-4 d}\right)^{2}\right. \\
& \left.+p\left[0, h_{1,2 t-4 n d-4 d}\right]+p\left[v_{2}, h_{2,2 t-4 n d-4 d}\right]\right)(x) \\
= & \frac{\partial}{\partial t} 2^{-1}\left(q_{2}^{3}(x, t)\right)^{2} .
\end{aligned}
$$

The above, (3.56) and the definition of $J_{n}^{3}$ imply

$\frac{\partial}{\partial t} 2^{-1}\left(q_{2}^{3}(x, t)\right)^{2} \leqq \delta / 2-\delta g_{2}(x)+v_{2}(x) \cdot \nabla\left(2^{-1}\left(q_{2, t}^{3}\right)^{2}+p\left[0, q_{1, t}^{3}\right]+p\left[v_{2}, q_{2, t}^{3}\right]\right)(x)$.

Using (3.58), (3.12) we obtain

$$
\frac{\partial}{\partial t} 2^{-1}\left(q_{1}^{3}(x, t)\right)^{2}=\frac{\partial}{\partial t} 2^{-1}\left(h_{1}(x, t)\right)^{2}=-\delta g_{1}(x) \text { if } t \in J_{n}^{3} .
$$

Conclusion (3.41) follows from (3.71)-(3.75).

Lemma 3.3. There exists $v_{0}>0$ such that the 5-tuple

$$
\left(h_{1,0}+h_{2,0}, h_{1, T}+h_{2, T}, 0, T, v\right)
$$

is $P$-admissible when $0<v<v_{0}$.

Proof. We recall Lemmas 3.1, 3.2. For $n \in\{0,1,2, \ldots, N-1\}$ we define $a_{n}^{1}=4 n d$, $b_{n}^{1}=a_{n}^{2}=4 n d+d, b_{n}^{2}=a_{n}^{3}=4 n d+2 d, b_{n}^{3}=4 n d+4 d$. Let $z \in\{1,2,3\}$ and $n$ be fixed. From (3.9) and (3.4) we conclude $\operatorname{spt}\left(v_{i}\right) \subset\left\{x: g_{i}(x)=1\right\} \subset \operatorname{spt}\left(f_{i}\right)$. Using (3.3), (3.4) we find that $\operatorname{spt}\left(f_{1}\right)$ and $\operatorname{spt}\left(f_{2}\right)$ are disjoint. Properties (3.11), (3.38), (3.9), (3.4) imply $q_{i}^{z}(x, t)=0$ if $x \notin \operatorname{spt}\left(f_{i}\right)$. Using (3.38), (3.15), (3.9) we obtain $L\left(q_{i, t}^{z}\right)(x) \geqq 0$ if $x \notin\left\{x: g_{i}(x)=1\right\}$. All this, the hypotheses of this section, and Lemmas 3.1, 3.2 imply that (2.1)-(2.9) are satisfied if $a, b, J, C_{i}, C_{i}^{\prime}, S_{i}, \eta, v_{i}, q_{i}$ are $a_{n}^{z}, b_{n}^{z}, J^{z}, \operatorname{spt}\left(f_{i}\right),\left\{x: g_{i}(x)=1\right\}, S_{i}^{z}, \delta / 2, v_{i}^{z}, q_{i}^{z}$, respectively. Now Lemma 2.1 implies that there exist positive numbers $v_{n}^{1}, v_{n}^{2}, v_{n}^{3}$ such that the 5-tuple

$$
\left(q_{1,4 n d}^{1}+q_{2,4 n d}^{1}, q_{1,4 n d+d}^{1}+q_{2,4 n d+d}^{1}, 4 n d, 4 n d+d, v\right)
$$

is $P$-admissible if $0<v<v_{n}^{1}$, the 5-tuple

$$
\left(q_{1,4 n d+d}^{2}+q_{2,4 n d+d}^{2}, q_{1,4 n d+2 d}^{2}+q_{2,4 n d+2 d}^{2}, 4 n d+d, 4 n d+2 d, v\right)
$$


is $P$-admissible if $0<v<v_{n}^{2}$, and the 5-tuple

$$
\left(q_{1,4 n d+2 d}^{3}+q_{2,4 n d+2 d}^{3}, q_{1,4 n d+4 d}^{3}+q_{2,4 n d+4 d}^{3}, 4 n d+2 d, 4 n d+4 d, v\right)
$$

is $P$-admissible if $0<v<v_{n}^{3}$. The conclusion follows from the above, Lemma 2.2, (3.34), (3.37), (3.40), and the choice of $v_{0}$ such that $v_{0}>0$ and $v_{0}<v_{n}^{z}$ for all $z$ and $n$.

\section{Section 4. The Geometric Arrangement}

Throughout this section, we fix $F, A, B, C, D$ such that (4.1)-(4.4) are satisfied:

$$
\begin{gathered}
F=\left(F_{1}, F_{2}\right) \text { is a } C^{\infty} \text { function from } R^{2} \text { into } R^{2}, \\
A, B, C, D \text { are real numbers, } B>0, C>0, D>0, \\
F_{1}(A, 0)=B, \quad \text { if } x \in R \text { then }\left|F_{1}(x, 0)\right| \leqq B \text { and } F_{2}(x, 0)=0, \\
\lim _{x \rightarrow \infty} x^{4} F_{1}(x, 0)=D, \text { if } x \in R^{2} \text { then }|F(x)| \leqq C|x|^{-4} \\
\text { and }|\nabla F(x)| \leqq C|x|^{-5} .
\end{gathered}
$$

When $\alpha \in R, \rho>0, \sigma>0$ we let $F^{\alpha, \rho, \sigma}=\left(F_{1}^{\alpha, \rho, \sigma}, F_{2}^{\alpha, \rho, \sigma}\right)$ be the $C^{\infty}$ function from $R^{2}$ into $R^{2}$ which is defined by

$$
F^{\alpha, \rho, \sigma}\left(x_{1}, x_{2}\right)=\left(\sigma^{2} / \rho\right) F\left(\left(x_{1}-\alpha\right) / \rho, x_{2} / \rho\right) \text { if }\left(x_{1}, x_{2}\right) \in R^{2} .
$$

From (4.1)-(4.3) we conclude the existence of $G$ with the properties

$$
0<G<\left(6 C^{1 / 4} B^{-1 / 4}+|A|\right) / 8, \quad \text { if }|x-A| \leqq G \text { then } F_{1}(x, 0)>(.999) B .
$$

Lemma 4.1. If $\alpha \in R, \rho>0, \sigma>0$ and $\alpha=A-\rho$ A then the following two properties are satisfied:

$$
\begin{aligned}
& \text { if }|x-A| \geqq\left(6 C^{1 / 4} B^{-1 / 4}+|A|\right) \rho, \text { then } F_{1}^{\alpha, \rho, \sigma}(x, 0)>-10^{-3}\left(\sigma^{2} / \rho\right) B \\
& \text { if }|x-A| \leqq G \rho, \text { then } F_{1}^{\alpha, \rho, \sigma}(x, 0)>(.999)\left(\sigma^{2} / \rho\right) B .
\end{aligned}
$$

Proof. If $|x-A| \geqq\left(6 C^{1 / 4} B^{-1 / 4}+|A|\right) \rho$, then the hypothesis $\alpha=A-\rho A$ implies

$$
\begin{aligned}
|x-\alpha| & =|(x-\alpha-\rho A)+\rho A|=|(x-A)+\rho A| \\
& \geqq|x-A|-\rho|A| \geqq\left(6 C^{1 / 4} B^{-1 / 4}+|A|\right) \rho-\rho|A|=6 C^{1 / 4} B^{-1 / 4} \rho .
\end{aligned}
$$

The above and (4.5), (4.4), (4.2) yield

$$
\begin{aligned}
\left|F_{1}^{\alpha, \rho, \sigma}(x, 0)\right| & =\left(\sigma^{2} / \rho\right)\left|F_{1}((x-\alpha) / \rho, 0)\right| \leqq\left(\sigma^{2} / \rho\right) C|x-\alpha|^{-4} \rho^{4} \\
& \leqq\left(\sigma^{2} / \rho\right) C\left(6 C^{1 / 4} B^{-1 / 4} \rho\right)^{-4} \rho^{4}=\left(\sigma^{2} / \rho\right) 6^{-4} B<10^{-3}\left(\sigma^{2} / \rho\right) B .
\end{aligned}
$$

This proves the first property. If $|x-A| \leqq G \rho$, then $\alpha=A-\rho A$ implies $|(x-\alpha) / \rho-A|=|x-\alpha-\rho A| / \rho=|x-A| / \rho \leqq G$. This inequality, (4.5) and (4.6) imply

$$
F_{1}^{\alpha, \rho, \sigma}(x, 0)=\left(\sigma^{2} / \rho\right) F_{1}((x-\alpha) / \rho, 0)>\left(\sigma^{2} / \rho\right)(.999) B,
$$

which yields the second property. 
Let $a^{\prime}, a^{\prime \prime}, r^{\prime}, r^{\prime \prime}, s^{\prime}, s^{\prime \prime}$ be the real numbers determined by (4.7) and (4.8):

$$
\begin{aligned}
& r^{\prime}=G /\left(6 C^{1 / 4} B^{-1 / 4}+|A|\right)>0, \quad r^{\prime \prime}=\left(r^{\prime}\right)^{2}>0, \\
& a^{\prime}=A-r^{\prime} A, \quad a^{\prime \prime}=A-r^{\prime \prime} A, \quad s^{\prime}=\left(2 r^{\prime}\right)^{1 / 2}>0, \quad s^{\prime \prime}=\left(4 r^{\prime \prime}\right)^{1 / 2}>0 .
\end{aligned}
$$

From (4.5), (4.3), (4.8) we conclude

$$
\left(F_{1}^{a^{\prime}, r^{\prime}, s^{\prime}}+F_{1}^{a^{\prime \prime}, r^{\prime \prime}, s^{\prime \prime}}+F_{1}\right)(A, 0)=2 B+4 B+B=7 B
$$

Using (4.7) and (4.6) we find

$$
0<r^{\prime}<1 / 8, \quad 0<r^{\prime \prime}<r^{\prime} / 8 .
$$

Lemma 4.2. If $x \in R$, then $\left(F_{1}^{a^{\prime}, r^{\prime}, s^{\prime}}+F_{1}^{a^{\prime \prime}, r^{\prime \prime}, s^{\prime \prime}}+F_{1}\right)(x, 0) \geqq-(1.006) B$.

Proof. The fact $G r^{\prime}<G$ (see (4.6), (4.10)) allows us to separate the argument into the following three cases: $|x-A| \leqq G r^{\prime}, G r^{\prime} \leqq|x-A| \leqq G,|x-A| \geqq G$. If $|x-A| \leqq G r^{\prime}$, then $|x-A|<G$ (see above). Hence (4.5), (4.7), (4.8), Lemma 4.1, (4.3), (4.6), (4.2) imply (in the first case)

$$
\begin{aligned}
\left(F_{1}^{a^{\prime}, r^{\prime}, s^{\prime}}+F_{1}^{a^{\prime \prime}, r^{\prime \prime}, s^{\prime \prime}}+F_{1}\right)(x, 0) & \geqq(.999)\left(\left(s^{\prime}\right)^{2} / r^{\prime}\right) B-\left(\left(s^{\prime \prime}\right)^{2} / r^{\prime \prime}\right) B+(.999) B \\
& =(.999)(2 B)-4 B+(.999) B>-(1.006) B .
\end{aligned}
$$

If $G r^{\prime} \leqq|x-A| \leqq G$, then (4.7) yields

$$
|x-A| \geqq G r^{\prime}=\left(6 C^{1 / 4} B^{-1 / 4}+|A|\right)\left(r^{\prime}\right)^{2}=\left(6 C^{1 / 4} B^{-1 / 4}+|A|\right) r^{\prime \prime} .
$$

Hence (4.5), (4.3), (4.7), (4.8), Lemma 4.1, (4.6), (4.2) imply

$$
\begin{aligned}
\left(F_{1}^{a^{\prime}, r^{\prime}, s^{\prime}}+F_{1}^{a^{\prime \prime}, r^{\prime \prime}, s^{\prime \prime}}+F_{1}\right)(x, 0) & \geqq-\left(\left(s^{\prime}\right)^{2} / r^{\prime}\right) B-10^{-3}\left(\left(s^{\prime \prime}\right)^{2} / r^{\prime \prime}\right) B+(.999) B \\
& =-2 B-10^{-3}(4 B)+(.999) B>-(1.006) B .
\end{aligned}
$$

If $|x-A| \geqq G$, then (4.7), (4.10) yield

$$
|x-A| \geqq G=\left(6 C^{1 / 4} B^{-1 / 4}+|A|\right) r^{\prime}>\left(6 C^{1 / 4} B^{-1 / 4}+|A|\right) r^{\prime \prime} .
$$

Hence (4.3), (4.7), (4.8), Lemma 4.1 imply

$$
\begin{aligned}
\left(F_{1}^{a^{\prime}, r^{\prime}, s^{\prime}}+F_{1}^{a^{\prime \prime}, r^{\prime \prime}, s^{\prime \prime}}+F_{1}\right)(x, 0) & \geqq-10^{-3}\left(\left(s^{\prime}\right)^{2} / r^{\prime}\right) B-10^{-3}\left(\left(s^{\prime \prime}\right)^{2} / r^{\prime \prime}\right) B-B \\
& =-10^{-3}(2 B)-10^{-3}(4 B)-B=-(1.006) B .
\end{aligned}
$$

Lemma 4.3. There exists $E$ such that (4.11)-(4.13) hold:

$$
E>0, \quad E<r^{\prime \prime} / 8<r^{\prime} / 8<1 / 8,
$$

if $x_{1} \in R$ and $\left|x_{2}\right| \leqq E$, then $\left(F_{1}^{a^{\prime}, r^{\prime}, s^{\prime}}+F_{1}^{a^{\prime \prime}, r^{\prime \prime}, s^{\prime \prime}}+F_{1}\right)\left(x_{1}, x_{2}\right)>-(1.01) B$,

$$
\begin{aligned}
& \text { if }\left|x_{1}-A\right| \leqq\left(10^{4} C / D\right) E \text { and }\left|x_{2}\right| \leqq E \text {, } \\
& \text { then }\left(F_{1}^{a^{\prime}, r^{\prime}, s^{\prime}}+F_{1}^{a^{\prime \prime}, r^{\prime \prime}, s^{\prime \prime}}+F_{1}\right)\left(x_{1}, x_{2}\right) \geqq(6.99) B \text {. }
\end{aligned}
$$

Proof. This follows from (4.10), Lemma 4.2, (4.5), (4.1), (4.4), (4.2), (4.9). 
Lemma 4.4. If $x \in R^{2},|x|>2|A|$, then $\left|\left(F^{a^{\prime}, r^{\prime}, s^{\prime}}+F^{a^{\prime \prime}, r^{\prime \prime}, s^{\prime \prime}}+F\right)(x)\right| \leqq 2 C|x|^{-4}$.

Proof. Using (4.8), (4.10), $\left|\left(x_{1}, x_{2}\right)\right|>2|A|$ we find

$$
\begin{aligned}
\left|\left(x_{1}-a^{\prime}, x_{2}\right)\right| & \geqq\left|\left(x_{1}, x_{2}\right)\right|-\left|a^{\prime}\right|=\left|\left(x_{1}, x_{2}\right)\right|-\left(1-r^{\prime}\right)|A| \\
& \geqq\left|\left(x_{1}, x_{2}\right)\right|-|A|>\left|\left(x_{1}, x_{2}\right)\right| / 2 .
\end{aligned}
$$

Then (4.5), (4.7), (4.8), (4.4), the above and (4.10) imply

$$
\begin{aligned}
\left|F^{a^{\prime}, r^{\prime}, s^{\prime}}\left(x_{1}, x_{2}\right)\right| & =\left(\left(s^{\prime}\right)^{2} / r^{\prime}\right)\left|F\left(\left(x_{1}-a^{\prime}\right) / r^{\prime}, x_{2} / r^{\prime}\right)\right| \\
& =2\left|F\left(\left(x_{1}-a^{\prime}\right) / r^{\prime}, x_{2} / r^{\prime}\right)\right| \leqq 2 C\left|\left(x_{1}-a^{\prime}, x_{2}\right)\right|^{-4}\left(r^{\prime}\right)^{4} \\
& \leqq 2 C\left|\left(x_{1}, x_{2}\right)\right|^{-4} 2^{4}\left(r^{\prime}\right)^{4} \leqq 2 C\left|\left(x_{1}, x_{2}\right)\right|^{-4} 4^{-4}
\end{aligned}
$$

A similar argument yields $\left|F^{a^{\prime \prime}, r^{\prime \prime}, s^{\prime \prime}}\left(x_{1}, x_{2}\right)\right| \leqq 4 C\left|\left(x_{1}, x_{2}\right)\right|^{-4} 4^{-4}$ if $\left|\left(x_{1}, x_{2}\right)\right|>2|A|$. The conclusion follows from all this and (4.4).

Assumptions (4.2), (4.4) imply that we can choose $M$ large enough to satisfy (4.14)-(4.16):

$$
M \geqq 1+10^{4} C / D,
$$

if $m \geqq M \quad$ and $\quad\left|x_{1}-m\right| \leqq 10^{4} C / D, \quad$ then $\left|m^{4} F_{1}\left(x_{1}, 0\right)-D\right| \leqq(.0005) D$,

if $m \geqq M, \quad$ then $C\left(m-10^{4} C / D\right)^{-5} \leqq(.0005) m^{-4} D$.

If $m \geqq M,\left|x_{1}-m\right| \leqq 10^{4} C / D$ and $\left|x_{2}\right| \leqq 1$ then the mean value theorem, (4.4), (4.14) and (4.16) yield

$$
\begin{aligned}
\left|F_{1}\left(x_{1}, x_{2}\right)-F_{1}\left(x_{1}, 0\right)\right| & \leqq\left|x_{2}\right|\left|\nabla F_{1}\left(x_{1}, \xi\right)\right| \leqq\left|x_{2}\right| C x_{1}^{-5} \leqq C x_{1}^{-5} \\
& \leqq C\left(m-10^{4} C / D\right)^{-5} \leqq(.0005) m^{-4} D .
\end{aligned}
$$

The above and (4.15) give us

$$
\text { if } \begin{aligned}
m & \geqq M, \quad\left|x_{1}-m\right| \leqq 10^{4} C / D, \quad\left|x_{2}\right| \leqq 1 \text { then }\left|F_{1}\left(x_{1}, x_{2}\right)-m^{-4} D\right| \\
& \leqq 10^{-3} m^{-4} D .
\end{aligned}
$$

We choose $\varepsilon>0$ small enough to satisfy (4.18) and (4.19):

$$
\begin{gathered}
\varepsilon^{-1}\left(1+\varepsilon^{2}\right)^{1 / 2} E / 10>2|A|+1, \quad 2 C\left(\varepsilon^{-1}\left(1+\varepsilon^{2}\right)^{1 / 2} E / 10\right)^{-4}<10^{-3} \varepsilon^{2} B \\
0<\varepsilon<.01, \quad \varepsilon^{-1} 10^{3} C / D>M, \quad \varepsilon^{-1} 10^{2} C / D>10^{4} C / D, \quad(.99)\left(1+\varepsilon^{2}\right)^{1 / 2}<1 .
\end{gathered}
$$

We set

$$
\begin{gathered}
r=\varepsilon^{-1}\left(1+\varepsilon^{2}\right)^{1 / 2} E, \quad a=-r\left(\varepsilon^{-1} 10^{3} C / D\right), \\
d=r\left(10^{4} C / D\right), \quad s=\left[((1.02) B /(.999))\left(\varepsilon^{-1} 10^{3} C / D\right)^{4}(r / D)\right]^{1 / 2} .
\end{gathered}
$$


Using (4.20), we can rewrite (4.18) and the last inequality in (4.19) in the form

$$
r / 10>2|A|+1, \quad 2 C(r / 10)^{-4}<10^{-3} \varepsilon^{2} B, \quad(.99) r \varepsilon<E .
$$

From (4.2), (4.4), (4.21) we get

$$
C / D \geqq 1, \quad \text { hence } d \geqq 10^{4} r .
$$

If $\left|x_{1}-A\right| \leqq\left(10^{4} C / D\right) E$, then (4.22), (4.21), (4.23), (4.20), (4.19), (4.23) allow us to write

$$
\left|x_{1}\right| \leqq|A|+\left(10^{4} C / D\right) E<r / 20+d(E / r)<10^{-4} d / 20+d \varepsilon<\left(1-10^{-4}\right) d \leqq d-r .
$$

The above, (4.19) and (4.20) imply

$$
\left[A-\left(10^{4} C / D\right) E, A+\left(10^{4} C / D\right) E\right] \subset(r-d, d-r) \text { and } E<r / 10 .
$$

Lemma 4.5. If $-d \leqq x_{1} \leqq d$ and $0 \leqq x_{2} \leqq r$, then

$$
\left|F_{2}^{a, r, s}\left(x_{1}, x_{2}\right)\right| \leqq(.002) B \varepsilon \text { and }(1.02) B \leqq F_{1}^{a, r, s}\left(x_{1}, x_{2}\right)<(1.03) B \text {. }
$$

Proof. Using (4.5), (4.20), (4.3), the mean value theorem, (4.4), our assumptions on $x_{i}$, (4.19) and (4.21) we obtain

$$
\begin{aligned}
\left|F_{2}^{a, r, s}\left(x_{1}, x_{2}\right)\right| & =\left(s^{2} / r\right)\left|F_{2}\left(x_{1} / r+\varepsilon^{-1} 10^{3} C / D, x_{2} / r\right)\right| \\
& =\left(s^{2} / r\right)\left|F_{2}\left(x_{1} / r+\varepsilon^{-1} 10^{3} C / D, x_{2} / r\right)-F_{2}\left(x_{1} / r+\varepsilon^{-1} 10^{3} C / D, 0\right)\right| \\
& \leqq\left(s^{2} / r\right)\left(x_{2} / r\right)\left|\nabla F_{2}\left(x_{1} / r+\varepsilon^{-1} 10^{3} C / D, \xi\right)\right| \\
& \leqq\left(s^{2} / r\right) C\left(x_{1} / r+\varepsilon^{-1} 10^{3} C / D\right)^{-5} \\
& \leqq\left(s^{2} / r\right) C\left(\varepsilon^{-1} 10^{3} C / D-10^{4} C / D\right)^{-5} \leqq\left(s^{2} / r\right) C\left((.9) \varepsilon^{-1} 10^{3} C / D\right)^{-5} \\
& =((1.02) B /(.999))\left(\varepsilon^{-1} 10^{3} C / D\right)^{-1}(C / D)(.9)^{-5}<(.002) B \varepsilon,
\end{aligned}
$$

which gives us the first conclusion. Using (4.5), (4.20) we find

$$
\left(s^{2} / r\right)^{-1} F_{1}^{a, r, s}\left(x_{1}, x_{2}\right)=F_{1}\left(\left(x_{1}-a\right) / r, x_{2} / r\right)=F_{1}\left(x_{1} / r+\varepsilon^{-1} 10^{3} C / D, x_{2} / r\right) .
$$

If we set $m=\varepsilon^{-1} 10^{3} C / D$, then the above, our assumptions on $x_{i}$, (4.17), (4.19) and (4.21) yield

$$
\left|\left(s^{2} / r\right)^{-1} F_{1}^{a, r, s}\left(x_{1}, x_{2}\right)-\left(\varepsilon^{-1} 10^{3} C / D\right)^{-4} D\right| \leqq 10^{-3}\left(\varepsilon^{-1} 10^{3} C / D\right)^{-4} D .
$$

Substituting (4.21) into this inequality, we obtain

$$
\left|F_{1}^{a, r, s}\left(x_{1}, x_{2}\right)-(1.02) B /(.999)\right| \leqq 10^{-3}(1.02) B /(.999),
$$

which implies the second conclusion.

Lemma 4.6. If $-d \leqq x_{1} \leqq d$ and $0 \leqq x_{2} \leqq E$, then

$$
\left(F_{1}^{a, r, s}+F_{1}^{a^{\prime}, r^{\prime}, s^{\prime}}+F_{1}^{a^{\prime \prime}, r^{\prime \prime}, s^{\prime \prime}}+F_{1}\right)\left(x_{1}, x_{2}\right) \geqq(.01) B .
$$


Proof. This follows from Lemma 4.5, (4.12) and (4.24).

Lemma 4.7. If $\left|x_{1}-A\right| \leqq\left(10^{4} C / D\right) E$ and $0 \leqq x_{2} \leqq E$, then

$$
\left(F_{1}^{a, r, s}+F_{1}^{a^{\prime}, r^{\prime}, s^{\prime}}+F_{1}^{a^{\prime \prime}, r^{\prime \prime}, s^{\prime \prime}}+F_{1}\right)\left(x_{1}, x_{2}\right) \geqq(8.01) B .
$$

Proof. This is a consequence of Lemma 4.5, (4.13) and (4.24).

Lemma 4.8. There exists $w \in C_{c}^{\infty}\left(P, R^{2}\right)$ such that we have

$$
\operatorname{spt}(w) \subset(-d, d) \times\left(10^{-3} \varepsilon r, r\right),
$$

$\operatorname{spt}(w)$ and $[r-d, d-r] \times[E, r / 10]$ are disjoint,

$$
x_{2} \frac{\partial}{\partial x_{1}} w_{1}\left(x_{1}, x_{2}\right)+x_{2} \frac{\partial}{\partial x_{2}} w_{2}\left(x_{1}, x_{2}\right)+w_{2}\left(x_{1}, x_{2}\right)=0,
$$

and the function $h\left(x_{1}, x_{2}\right)=w\left(x_{1}, x_{2}\right) \cdot\left(F^{a, r, s}+F^{a^{\prime}, r^{\prime}, s^{\prime}}+F^{a^{\prime \prime}, r^{\prime \prime}, s^{\prime \prime}}+F\right)\left(x_{1}, x_{2}\right)$ satisfies (4.28)-(4.30):

if $\left|x_{1}-A\right| \leqq\left(10^{4} C / D\right) E$ and $(.02) \varepsilon r \leqq x_{2} \leqq(.98) \varepsilon r$, then $h\left(x_{1}, x_{2}\right) \geqq(8.01) B$,

if $\left|x_{1}\right| \leqq d-r$ and $(.02) \varepsilon r \leqq x_{2} \leqq(.98) \varepsilon r$, then $h\left(x_{1}, x_{2}\right) \geqq(.01) B$, (4.29)

$$
\text { if } x \in P \text {, then } h(x) \geqq-\varepsilon^{2}(1.032) B
$$

Proof. We set (see Fig. 1)

$$
\begin{aligned}
H_{1} & =\left\{\left(x_{1}, x_{2}\right): x_{2}=\varepsilon\left(x_{1}+d\right),(.01) \varepsilon r \leqq x_{2} \leqq(.99) \varepsilon r\right\}, \\
H_{2} & =\left\{\left(x_{1}, x_{2}\right):\left(x_{1}+d\right) x_{2}=(.9801) \varepsilon r^{2},(.99) \varepsilon r \leqq x_{2} \leqq(.0199)^{1 / 2} r\right\}, \\
H_{3} & =\left\{\left(x_{1}, x_{2}\right): x_{1}+d=\varepsilon\left(r^{2}-x_{2}^{2}\right) / x_{2},(.0199)^{1 / 2} r \leqq x_{2} \leqq(.9999)^{1 / 2} r\right\}, \\
H_{4} & =\left\{\left(x_{1}, x_{2}\right):\left(x_{1}+d\right) x_{2}=(.0001) \varepsilon r^{2},(.01) \varepsilon r \leqq x_{2} \leqq(.9999)^{1 / 2} r\right\}, \\
H_{i+4} & =\left\{\left(x_{1}, x_{2}\right):\left(-x_{1}, x_{2}\right) \in H_{i}\right\} \text { for } i=1,2,3,4,
\end{aligned}
$$

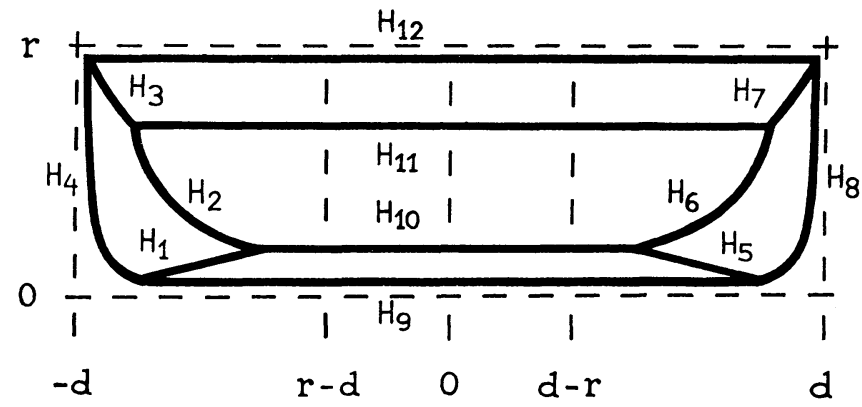

Fig. 1 


$$
\begin{aligned}
H_{9} & =\left\{\left(x_{1}, x_{2}\right):\left|x_{1}\right| \leqq d-(.01) r, x_{2}=(.01) \varepsilon r\right\}, \\
H_{10} & =\left\{\left(x_{1}, x_{2}\right):\left|x_{1}\right| \leqq d-(.99) r, x_{2}=(.99) \varepsilon r\right\}, \\
H_{11} & =\left\{\left(x_{1}, x_{2}\right):\left|x_{1}\right| \leqq d-\left((.9801) /(.0199)^{1 / 2}\right) \varepsilon r, x_{2}=(.0199)^{1 / 2} r\right\}, \\
H_{12} & =\left\{\left(x_{1}, x_{2}\right):\left|x_{1}\right| \leqq d-\left((.0001) /(.9999)^{1 / 2}\right) \varepsilon r, x_{2}=(.9999)^{1 / 2} r\right\} .
\end{aligned}
$$

The topological notions of this paragraph will always refer to the natural topology of $P\left(\right.$ not $\left.R^{2}\right)$. The sets $R_{1}, \ldots, R_{6}$ are open subsets of $P$ determined by the following conditions: $R_{1}, \ldots, R_{5}$ are bounded, $R_{6}$ is unbounded,

$$
\begin{gathered}
H_{1} \cup H_{10} \cup H_{5} \cup H_{9}=\operatorname{boundary}\left(R_{1}\right), H_{5} \cup H_{6} \cup H_{7} \cup H_{8}=\operatorname{boundary}\left(R_{2}\right), \\
H_{3} \cup H_{12} \cup H_{7} \cup H_{11}=\operatorname{boundary}\left(R_{3}\right), H_{1} \cup H_{2} \cup H_{3} \cup H_{4}=\operatorname{boundary}\left(R_{4}\right), \\
H_{2} \cup H_{10} \cup H_{6} \cup H_{11}=\operatorname{boundary}\left(R_{5}\right), H_{9} \cup H_{8} \cup H_{12} \cup H_{4}=\operatorname{boundary}\left(R_{6}\right) .
\end{gathered}
$$

The function $v=\left(v_{1}, v_{2}\right)$ from $P$ into $R^{2}$ is defined almost everywhere by the equations

$$
\begin{aligned}
& v\left(x_{1}, x_{2}\right)=\left(x_{2}, 0\right) \quad \text { if }\left(x_{1}, x_{2}\right) \in R_{1}, \\
& v\left(x_{1}, x_{2}\right)=\left((\varepsilon / 2)\left(d-x_{1}\right),(\varepsilon / 2) x_{2}\right) \quad \text { if }\left(x_{1}, x_{2}\right) \in R_{2}, \\
& v\left(x_{1}, x_{2}\right)=\left(-\varepsilon^{2} x_{2}, 0\right) \quad \text { if }\left(x_{1}, x_{2}\right) \in R_{3}, \\
& v\left(x_{1}, x_{2}\right)=\left((\varepsilon / 2)\left(x_{1}+d\right),-(\varepsilon / 2) x_{2}\right) \quad \text { if }\left(x_{1}, x_{2}\right) \in R_{4}, \\
& v\left(x_{1}, x_{2}\right)=(0,0) \quad \text { if }\left(x_{1}, x_{2}\right) \in R_{5} \cup R_{6} .
\end{aligned}
$$

Let $v^{i}$ be the continuous function on closure $\left(R_{i}\right)$ that agrees with $v$ on $R_{i}$. If $H_{i}=\operatorname{closure}\left(R_{j}\right) \cap \operatorname{closure}\left(R_{k}\right)$ then the restrictions of $v^{j}$ and $v^{k}$ to $H_{i}$ have the same normal components with respect to $H_{i}$. If $f \in C_{c}^{\infty}(P, R)$ then $v \cdot \nabla f=\operatorname{div}(f v)$ is valid on each $R_{i}$. Hence, applying the divergence theorem to each $R_{i}$ and adding up the resulting six equations, we conclude

$$
\int_{P} v\left(x_{1}, x_{2}\right) \cdot \nabla f\left(x_{1}, x_{2}\right) d x_{1} d x_{2}=0 \quad \text { if } f \in C_{c}^{\infty}(P, R) .
$$

We have

$$
0<\varepsilon\left(d-x_{1}\right)<x_{2} \quad \text { if }\left(x_{1}, x_{2}\right) \in R_{2}, \quad 0<\varepsilon\left(x_{1}+d\right)<x_{2} \quad \text { if }\left(x_{1}, x_{2}\right) \in R_{4} .
$$

This implies $0<v_{1}\left(x_{1}, x_{2}\right)<x_{2} / 2$ if $\left(x_{1}, x_{2}\right) \in R_{2} \cup R_{4}$. Combining this with $0<\varepsilon<1$ (see (4.19)) we conclude

$$
\left|v\left(x_{1}, x_{2}\right)\right| \leqq x_{2}, \quad v_{1}\left(x_{1}, x_{2}\right) \geqq-\varepsilon^{2} x_{2}, \quad\left|v_{2}\left(x_{1}, x_{2}\right)\right| \leqq(\varepsilon / 2) x_{2}
$$

for almost every $\left(x_{1}, x_{2}\right) \in P$. Using $(.99) \varepsilon r<E<r / 10<(.0199)^{1 / 2} r$ (see (4.22), (4.24)) we obtain

$$
\begin{aligned}
& \operatorname{spt}(v) \subset(-d, d) \times\left[10^{-2} \varepsilon r, r\right), \\
& \operatorname{spt}(v) \text { and }[r-d, d-r] \times[E, r / 10] \text { are disjoint sets. }
\end{aligned}
$$

Hence we can choose $g \in C_{c}^{\infty}\left(R^{2}, R\right)$ such that (extending $v$ by 0 to all of $R^{2}$ ) we get

$$
g(x) \geqq 0,\|g\|_{1}=1, g(x)=g(y) \quad \text { if }|x|=|y|, g(x)=0 \quad \text { if }|x| \geqq 10^{-3} \varepsilon r,
$$




$$
\operatorname{spt}(v * g) \subset(-d, d) \times\left(10^{-3} \varepsilon r, r\right),
$$

$\operatorname{spt}(v * g)$ and $[r-d, d-r] \times[E, r / 10]$ are disjoint sets.

From (4.32), (4.33) and (4.35) we obtain

$$
\begin{aligned}
\left|(v * g)\left(x_{1}, x_{2}\right)\right| & \leqq x_{2},\left(v_{1} * g\right)\left(x_{1}, x_{2}\right) \geqq-\varepsilon^{2} x_{2}, \\
\left|\left(v_{2} * g\right)\left(x_{1}, x_{2}\right)\right| & \leqq(\varepsilon / 2) x_{2} \quad \text { if }\left(x_{1}, x_{2}\right) \in P .
\end{aligned}
$$

The definition of $v$ on $R_{1}, R_{5}, R_{6}, 0<\varepsilon<1$ (see (4.19)), $E<r / 10$ (see (4.24)) and (4.35) give us

$$
\begin{aligned}
& \text { if }\left|x_{1}\right| \leqq d-r \quad \text { and }(.02) \varepsilon r \leqq x_{2} \leqq(.98) \varepsilon r \quad \text { then }(v * g)\left(x_{1}, x_{2}\right)=\left(x_{2}, 0\right), \\
& \text { if }\left|x_{1}\right| \leqq d-r \quad \text { and } \quad 0<x_{2}<E \text { then }\left(v_{1} * g\right)\left(x_{1}, x_{2}\right) \geqq 0, \quad\left(v_{2} * g\right)\left(x_{1}, x_{2}\right)=0 .
\end{aligned}
$$

Recalling (4.36), we define $w \in C_{\mathrm{c}}^{\infty}\left(P, R^{2}\right)$ using the formula

$$
w\left(x_{1}, x_{2}\right)=x_{2}^{-1}(v * g)\left(x_{1}, x_{2}\right),
$$

and use (4.38), (4.39) to conclude

$$
\begin{aligned}
& |w(x)| \leqq 1, \quad w_{1}(x) \geqq-\varepsilon^{2}, \quad\left|w_{2}(x)\right| \leqq \varepsilon / 2 \text { if } x \in P, \\
& \text { if }\left|x_{1}\right| \leqq d-r \text { and }(.02) \varepsilon r \leqq x_{2} \leqq(.98) \varepsilon r, \text { then } w(x)=(1,0) .
\end{aligned}
$$

Conclusions (4.25), (4.26) follow from (4.41), (4.36), (4.37). Properties (4.31), (4.33) give us $\operatorname{div}(v * g)=0$, which implies (4.27). Using (4.43), (4.24), (4.22) and Lemma 4.7 we get (4.28). From (4.43), (4.22) and Lemma 4.6 we conclude (4.29). All we have to do now is prove $(4.30)$.

We may assume $\left(x_{1}, x_{2}\right) \in \operatorname{spt}(w)$. If $\left(x_{1}, x_{2}\right)$ satisfies $\left|\left(x_{1}, x_{2}\right)\right|>r / 10$, then (4.42), (4.25), Lemma 4.5, $2|A|<r / 10<\left|\left(x_{1}, x_{2}\right)\right|$ (see (4.22)), Lemma 4.4, (4.22) imply

$$
\begin{aligned}
w\left(x_{1}, x_{2}\right) \cdot\left(F^{a, r, s}+F^{a^{\prime}, r^{\prime}, s^{\prime}}+F^{a^{\prime \prime}, r^{\prime \prime}, s^{\prime \prime}}+F\right)\left(x_{1}, x_{2}\right) \\
=w_{1}\left(x_{1}, x_{2}\right) F_{1}^{a, r, s}\left(x_{1}, x_{2}\right)+w_{2}\left(x_{1}, x_{2}\right) F_{2}^{a, r, s}\left(x_{1}, x_{2}\right) \\
\quad+w\left(x_{1}, x_{2}\right) \cdot\left(F^{a^{\prime}, r^{\prime}, s^{\prime}}+F^{a^{\prime \prime}, r^{\prime \prime}, s^{\prime \prime}}+F\right)\left(x_{1}, x_{2}\right) \\
>-\varepsilon^{2}(1.03) B-(\varepsilon / 2)(.002) B \varepsilon-2 C\left|\left(x_{1}, x_{2}\right)\right|^{-4} \\
>-\varepsilon^{2}(1.031) B-2 C(r / 10)^{-4}>-\varepsilon^{2}(1.031) B-10^{-3} \varepsilon^{2} B=-\varepsilon^{2}(1.032) B .
\end{aligned}
$$

It remains to show that (4.30) holds if $\left|\left(x_{1}, x_{2}\right)\right| \leqq r / 10$. In this case, properties (4.23), $\left(x_{1}, x_{2}\right) \in \operatorname{spt}(w),(4.25)$ imply

$$
\left|x_{1}\right| \leqq r / 10 \leqq 10^{-5} d<\left(1-10^{-4}\right) d \leqq d-r, \quad 0<x_{2} \leqq r / 10 .
$$

The above and (4.26) imply $0<x_{2}<E$. Then (4.40), (4.41) yield $w_{1}\left(x_{1}, x_{2}\right) \geqq 0$, $w_{2}\left(x_{1}, x_{2}\right)=0$ and Lemma 4.6 gives us $h\left(x_{1}, x_{2}\right) \geqq 0$. The conclusion follows from this and (4.2).

\section{Section 5. Edge Effects}

Lemma 5.1. If $c \in R, s>0$ and $f:(c-s, c+s) \rightarrow R$ is $a C^{\infty}$ function such that

$$
f(x)=0 \quad \text { if } c-s<x \leqq c, f^{(3)}(x)>0 \text { if } c<x<c+s,
$$


then every $x \in(c, c+s)$ satisfies

$$
f^{\prime \prime}(x)>0, \quad 0<f(x)<(x-c)^{2} f^{\prime \prime}(x), \quad 0<f^{\prime}(x)<(x-c) f^{\prime \prime}(x) .
$$

Proof. If $c<x<c+s$ then the theory of divided differences (see [2], pp. 41, 52) and $c-s<2 c-x<c$ imply that there exists $\xi \in(2 c-x, x)$ such that

$$
\begin{aligned}
f(x) & =f(2 c-x)-2 f(c)+f(x)=2(x-c)^{2} f[2 c-x, c, x] \\
& =2(x-c)^{2} f^{\prime \prime}(\xi) / 2<(x-c)^{2} f^{\prime \prime}(x) .
\end{aligned}
$$

The remaining conclusions follow from the mean value theorem.

Lemma 5.2. If $c \in R, s>0$ and $f:(c-s, c+s) \rightarrow R$ is a $C^{\infty}$ function such that

$$
f^{(3)}(x)<0 \text { if } c-s<x<c, f(x)=0 \quad \text { if } c \leqq x<c+s,
$$

then every $x \in(c-s, c)$ satisfies

$$
f^{\prime \prime}(x)>0, \quad 0<f(x)<(x-c)^{2} f^{\prime \prime}(x), \quad(x-c) f^{\prime \prime}(x)<f^{\prime}(x)<0 .
$$

Proof. This is a consequence of Lemma 5.1 and a reflection of $f$.

Lemma 5.3. Suppose $a_{1}<b_{1}, 0<a_{2}<b_{2}, \varepsilon>0, b_{i}-a_{i}>2 \varepsilon$ for each $i, f_{1}$ and $f_{2}$ are $C^{\infty}$ functions from $R$ into $R, h\left(x_{1}, x_{2}\right)=f_{1}\left(x_{1}\right) f_{2}\left(x_{2}\right)$ and the following properties hold for each $i \in\{1,2\}$ :

$$
\begin{aligned}
f_{i}(x)>0 & \text { if } a_{i}<x<b_{i}, \quad f_{i}(x)=0 \quad \text { if } x \notin\left(a_{i}, b_{i}\right), \\
f_{i}^{(3)}(x)>0 & \text { if } a_{i}<x<a_{i}+\varepsilon, \quad f_{i}^{(3)}(x)<0 \quad \text { if } b_{i}-\varepsilon<x<b_{i} .
\end{aligned}
$$

Then there exists $\delta>0$ such that the inequality

$$
L(h)\left(x_{1}, x_{2}\right) \equiv \Delta h\left(x_{1}, x_{2}\right)+x_{2}^{-1} \frac{\partial}{\partial x_{2}} h\left(x_{1}, x_{2}\right)-x_{2}^{-2} h\left(x_{1}, x_{2}\right)>0
$$

is satisfied for every point $\left(x_{1}, x_{2}\right)$ that has the properties

$$
\left(x_{1}, x_{2}\right) \in\left(a_{1}, b_{1}\right) \times\left(a_{2}, b_{2}\right), \quad\left(x_{1}, x_{2}\right) \notin\left[a_{1}+\delta, b_{1}-\delta\right] \times\left[a_{2}+\delta, b_{2}-\delta\right] .
$$

Proof. If $x_{1} \in R$ and $x_{2}>0$, we set

$$
g_{1}\left(x_{1}\right)=f_{1}^{\prime \prime}\left(x_{1}\right), \quad g_{2}\left(x_{2}\right)=f_{2}^{\prime \prime}\left(x_{2}\right)+f_{2}^{\prime}\left(x_{2}\right) / x_{2}-f_{2}\left(x_{2}\right) / x_{2}^{2} .
$$

This notation implies

$$
L(h)\left(x_{1}, x_{2}\right)=g_{1}\left(x_{1}\right) f_{2}\left(x_{2}\right)+f_{1}\left(x_{1}\right) g_{2}\left(x_{2}\right) .
$$

We may assume $\varepsilon / a_{2}<1 / 2, \varepsilon /\left(b_{2}-\varepsilon\right)<1 / 2$ without loss of generality. If $x_{2} \in\left(a_{2}, a_{2}+\varepsilon\right)$, then (5.1), Lemma 5.1 and $\varepsilon / a_{2}<1 / 2$ imply

$$
\begin{aligned}
g_{2}\left(x_{2}\right) & >f_{2}^{\prime \prime}\left(x_{2}\right)-f_{2}\left(x_{2}\right) / x_{2}^{2}>f_{2}^{\prime \prime}\left(x_{2}\right)-\left(x_{2}-a_{2}\right)^{2} f_{2}^{\prime \prime}\left(x_{2}\right) / x_{2}^{2} \\
& >\left(1-\left(\varepsilon / a_{2}\right)^{2}\right) f_{2}^{\prime \prime}\left(x_{2}\right)>(3 / 4) f_{2}^{\prime \prime}\left(x_{2}\right) .
\end{aligned}
$$

If $x_{2} \in\left(b_{2}-\varepsilon, b_{2}\right)$, then (5.1), Lemma 5.2 and $\varepsilon /\left(b_{2}-\varepsilon\right)<1 / 2$ imply

$$
\begin{aligned}
g_{2}\left(x_{2}\right) & >f_{2}^{\prime \prime}\left(x_{2}\right)+\left(x_{2}-b_{2}\right) f_{2}^{\prime \prime}\left(x_{2}\right) / x_{2}-\left(x_{2}-b_{2}\right)^{2} f_{2}^{\prime \prime}\left(x_{2}\right) / x_{2}^{2} \\
& >\left(1-\varepsilon /\left(b_{2}-\varepsilon\right)-\left(\varepsilon /\left(b_{2}-\varepsilon\right)\right)^{2}\right) f_{2}^{\prime \prime}\left(x_{2}\right)>f_{2}^{\prime \prime}\left(x_{2}\right) / 4 .
\end{aligned}
$$


From the above and Lemmas 5.1, 5.2 we obtain

$$
g_{k}\left(x_{k}\right)>f_{k}^{\prime \prime}\left(x_{k}\right) / 4>0 \quad \text { if } x_{k} \in\left(a_{k}, a_{k}+\varepsilon\right) \cup\left(b_{k}-\varepsilon, b_{k}\right) .
$$

The positivity of $f_{k}$ on $\left(a_{k}, b_{k}\right), b_{k}-a_{k}>2 \varepsilon,(5.2)$ and (5.3) yield

$$
L(h)\left(x_{1}, x_{2}\right)>0 \text { if } x_{k} \in\left(a_{k}, a_{k}+\varepsilon\right) \cup\left(b_{k}-\varepsilon, b_{k}\right) .
$$

There are numbers $m>0, M<\infty$ such that

$$
x_{k} \in\left[a_{k}+\varepsilon, b_{k}-\varepsilon\right] \text { implies } f_{k}\left(x_{k}\right)>m \text { and }\left|g_{k}\left(x_{k}\right)\right|<M \text {. }
$$

We can find $\delta>0$ such that $\delta<\varepsilon, m / 4-\delta^{2} M>0$. Now suppose that $(i, j)$ is a permutation of $(1,2)$ and the point $\left(x_{1}, x_{2}\right)$ satisfies

$$
x_{i} \in\left[a_{i}+\varepsilon, b_{i}-\varepsilon\right], \quad x_{j} \in\left(a_{j}, a_{j}+\delta\right) \cup\left(b_{j}-\delta, b_{j}\right) .
$$

The assumptions $b_{i}-a_{i}>2 \varepsilon, \delta<\varepsilon$ imply that $\left(a_{j}, a_{j}+\delta\right)$ and $\left(b_{j}-\delta, b_{j}\right)$ are disjoint. Hence we can define

$$
c=a_{j} \quad \text { if } x_{j} \in\left(a_{j}, a_{j}+\delta\right), \quad c=b_{j} \quad \text { if } x_{j} \in\left(b_{j}-\delta, b_{j}\right) .
$$

The properties $\delta<\varepsilon,(5.2),(5.3),(5.5),(5.6),(5.7)$ and Lemmas 5.1, 5.2 yield

$$
\begin{aligned}
L(h)\left(x_{1}, x_{2}\right) & =f_{i}\left(x_{i}\right) g_{j}\left(x_{j}\right)+f_{j}\left(x_{j}\right) g_{i}\left(x_{i}\right)>f_{i}\left(x_{i}\right) f_{j}^{\prime \prime}\left(x_{j}\right) / 4-f_{j}\left(x_{j}\right) M \\
& >m f_{j}^{\prime \prime}\left(x_{j}\right) / 4-\left(x_{j}-c\right)^{2} f_{j}^{\prime \prime}\left(x_{j}\right) M>\left(m / 4-\delta^{2} M\right) f_{j}^{\prime \prime}\left(x_{j}\right)>0 .
\end{aligned}
$$

This estimate and (5.4) imply that $L(h)$ is positive on the union of the sets

$$
\begin{aligned}
& \left(\left(a_{1}, a_{1}+\varepsilon\right) \cup\left(b_{1}-\varepsilon, b_{1}\right)\right) \times\left(\left(a_{2}, a_{2}+\varepsilon\right) \cup\left(b_{2}-\varepsilon, b_{2}\right)\right), \\
& {\left[a_{1}+\varepsilon, b_{1}-\varepsilon\right] \times\left(\left(a_{2}, a_{2}+\delta\right) \cup\left(b_{2}-\delta, b_{2}\right)\right),} \\
& \left(\left(a_{1}, a_{1}+\delta\right) \cup\left(b_{1}-\delta, b_{1}\right)\right) \times\left[a_{2}+\varepsilon, b_{2}-\varepsilon\right] .
\end{aligned}
$$

The conclusion of the lemma follows from this and $0<\delta<\varepsilon$.

Lemma 5.4. If $a_{1}<b, 0<a_{2}<b_{2}, d>0$ and $b_{i}-a_{i}>2 d$ for each $i$, then there exist $\delta>0$ and $a C^{\infty}$ function $h: R^{2} \rightarrow[0,1]$ such that $\delta<d$,

$$
\begin{aligned}
h\left(x_{1}, x_{2}\right)=0 & \text { if }\left(x_{1}, x_{2}\right) \notin\left(a_{1}, b_{1}\right) \times\left(a_{2}, b_{2}\right), \\
h\left(x_{1}, x_{2}\right)=1 & \text { if }\left(x_{1}, x_{2}\right) \in\left[a_{1}+d, b_{1}-d\right] \times\left[a_{2}+d, b_{2}-d\right], \\
0<h\left(x_{1}, x_{2}\right) \leqq 1 & \text { if }\left(x_{1}, x_{2}\right) \in\left(a_{1}, b_{1}\right) \times\left(a_{2}, b_{2}\right), \\
L(h)(x)>0 & \text { if } x \in\left(a_{1}, b_{1}\right) \times\left(a_{2}, b_{2}\right), x \notin\left[a_{1}+\delta, b_{1}-\delta\right] \times\left[a_{2}+\delta, b_{2}-\delta\right] .
\end{aligned}
$$

Proof. We can find $\varepsilon^{\prime}>0$ and $C^{\infty}$ functions $f_{i}: R \rightarrow[0,1]$ for $i=1,2$ such that $0<\varepsilon^{\prime}<d, \operatorname{spt}\left(f_{i}\right) \subset\left[a_{i}, b_{i}\right], f_{i}(x)>0$ if $x \in\left(a_{i}, b_{i}\right), f_{i}(x)=1$ if $x \in\left[a_{i}+d, b_{i}-d\right]$,

$$
\begin{array}{ll}
f_{i}(x)=\exp \left(-\left(x-a_{i}\right)^{-2}\right) & \text { if } a_{i}<x<a_{i}+\varepsilon^{\prime}, \\
f_{i}(x)=\exp \left(-\left(b_{i}-x\right)^{-2}\right) & \text { if } b_{i}-\varepsilon^{\prime}<x<b_{i} .
\end{array}
$$

Setting $k(x)=\exp \left(-x^{-2}\right)$ for $x>0$, we can find $\varepsilon$ such that $0<\varepsilon<\varepsilon^{\prime}$ and $k^{(3)}(x)>0$ for all $x \in(0, \varepsilon)$. Then $f_{i}^{(3)}(x)>0$ for $x \in\left(a_{i}, a_{i}+\varepsilon\right), f_{i}^{(3)}(x)<0$ for $x \in\left(b_{i}-\varepsilon, b_{i}\right)$. The conclusion follows from Lemma 5.3 and the definition $h\left(x_{1}, x_{2}\right)=f_{1}\left(x_{1}\right) f_{2}\left(x_{2}\right)$. 
Lemma 5.5. If $a_{1}<b_{1}$ and $0<d<a_{2}<b_{2}$, then there exist $\delta>0$ and $a C^{\infty}$ function $g: R^{2} \rightarrow[0,1]$ such that $\delta<d$,

$$
\begin{aligned}
g\left(x_{1}, x_{2}\right)=0 & \text { if }\left(x_{1}, x_{2}\right) \in\left[a_{1}, b_{1}\right] \times\left[a_{2}, b_{2}\right], \\
g\left(x_{1}, x_{2}\right)=1 & \text { if }\left(x_{1}, x_{2}\right) \notin\left(a_{1}-d, b_{1}+d\right) \times\left(a_{2}-d, b_{2}+d\right), \\
0<g\left(x_{1}, x_{2}\right) \leqq 1 & \text { if }\left(x_{1}, x_{2}\right) \notin\left[a_{1}, b_{1}\right] \times\left[a_{2}, b_{2}\right], \\
L(g)(x)>0 & \text { if } x \in\left(a_{1}-\delta, b_{1}+\delta\right) \times\left(a_{2}-\delta, b_{2}+\delta\right), \quad x \notin\left[a_{1}, b_{1}\right] \times\left[a_{2}, b_{2}\right] .
\end{aligned}
$$

Proof. We can find $\varepsilon^{\prime}>0$ and $C^{\infty}$ functions $f_{i}: R \rightarrow[0,1]$ for $i=1,2$ such that $\varepsilon^{\prime}<d, f_{i}(x)=0$ if $x \in\left[a_{i}, b_{i}\right], f_{i}(x)>0$ if $x \notin\left[a_{i}, b_{i}\right]$,

$$
\begin{array}{ll}
f_{i}(x)=\exp \left(-\left(a_{i}-x\right)^{-2}\right) & \text { if } a_{i}-\varepsilon^{\prime}<x<a_{i}, \\
f_{i}(x)=\exp \left(-\left(x-b_{i}\right)^{-2}\right) & \text { if } b_{i}<x<b_{i}+\varepsilon^{\prime} .
\end{array}
$$

As in the proof of Lemma 5.4, there exists $\varepsilon$ such that $0<\varepsilon<\varepsilon^{\prime}, f_{i}^{(3)}(x)<0$ if $x \in\left(a_{i}-\varepsilon, a_{i}\right), f_{i}^{(3)}(x)>0$ if $x \in\left(b_{i}, b_{i}+\varepsilon\right)$. Setting $h\left(x_{1}, x_{2}\right)=f_{1}\left(x_{1}\right)+f_{2}\left(x_{2}\right)$, we find

$$
L(h)\left(x_{1}, x_{2}\right)=\left(f_{1}^{\prime \prime}\left(x_{1}\right)-f_{1}\left(x_{1}\right) / x_{2}^{2}\right)+\left(f_{2}^{\prime \prime}\left(x_{2}\right)+f_{2}^{\prime}\left(x_{2}\right) / x_{2}-f_{2}\left(x_{2}\right) / x_{2}^{2}\right) .
$$

We may impose the conditions $\varepsilon /\left(a_{2}-\varepsilon\right)<1 / 2, \varepsilon / b_{2}<1 / 2$ on $\varepsilon$. If we use these conditions and interchange $a_{2}, b_{2}$ in the argument that led to (5.3), then we obtain

$$
f_{2}^{\prime \prime}\left(x_{2}\right)+f_{2}^{\prime}\left(x_{2}\right) / x_{2}-f_{2}\left(x_{2}\right) / x_{2}^{2}>0 \text { if } x_{2} \in\left(a_{2}-\varepsilon, a_{2}\right) \cup\left(b_{2}, b_{2}+\varepsilon\right) .
$$

Our definitions (which imply $a_{2}-\varepsilon>0$ ) give us

$$
\begin{array}{cl}
f_{2}^{\prime \prime}\left(x_{2}\right)+f_{2}^{\prime}\left(x_{2}\right) / x_{2}-f_{2}\left(x_{2}\right) / x_{2}^{2}=0 & \text { if } x_{2} \in\left[a_{2}, b_{2}\right], \\
f_{1}^{\prime \prime}\left(x_{1}\right)-f_{1}\left(x_{1}\right) / x_{2}^{2}=0 & \text { if } x_{1} \in\left[a_{1}, b_{1}\right] \text { and } x_{2}>a_{2}-\varepsilon .
\end{array}
$$

Now suppose $x_{1} \in\left(a_{1}-\varepsilon, a_{1}\right) \cup\left(b_{1}, b_{1}+\varepsilon\right)$ and $x_{2}>a_{2}-\varepsilon$. If we set

$$
c=a_{1} \quad \text { if } x_{1} \in\left(a_{1}-\varepsilon, a_{1}\right), \quad c=b_{1} \quad \text { if } x_{1} \in\left(b_{1}, b_{1}+\varepsilon\right),
$$

then Lemmas 5.1, 5.2 and $\varepsilon /\left(a_{2}-\varepsilon\right)<1 / 2$ yield

$$
\begin{aligned}
& f_{1}^{\prime \prime}\left(x_{1}\right)-f_{1}\left(x_{1}\right) / x_{2}^{2}>f_{1}^{\prime \prime}\left(x_{1}\right)-\left(x_{1}-c\right)^{2} f_{1}^{\prime \prime}\left(x_{1}\right) / x_{2}^{2}>\left(1-\left(\varepsilon /\left(a_{2}-\varepsilon\right)\right)^{2}\right) \\
& \cdot f_{1}^{\prime \prime}\left(x_{1}\right)>(3 / 4) f_{1}^{\prime \prime}\left(x_{1}\right)>0 .
\end{aligned}
$$

Combining this with (5.8)-(5.11) and the definition of $f_{i}$, we find that $L(h)(x)$ and $h(x)$ are positive when $x$ satisfies

$$
x \in\left(a_{1}-\varepsilon, b_{1}+\varepsilon\right) \times\left(a_{2}-\varepsilon, b_{2}+\varepsilon\right), \quad x \notin\left[a_{1}, b_{1}\right] \times\left[a_{2}, b_{2}\right] .
$$

We can construct a $C^{\infty}$ function $g: R^{2} \rightarrow[0,1]$ such that

$$
\begin{aligned}
g\left(x_{1}, x_{2}\right) & =1 \quad \text { if }\left(x_{1}, x_{2}\right) \notin\left(a_{1}-d, b_{1}+d\right) \times\left(a_{2}-d, b_{2}+d\right), \\
0<g\left(x_{1}, x_{2}\right) & \leqq 1 \quad \text { if }\left(x_{1}, x_{2}\right) \notin\left[a_{1}, b_{1}\right] \times\left[a_{2}, b_{2}\right], \\
g\left(x_{1}, x_{2}\right) & =h\left(x_{1}, x_{2}\right) \quad \text { if }\left(x_{1}, x_{2}\right) \in\left(a_{1}-\delta, b_{1}+\delta\right) \times\left(a_{2}-\delta, b_{2}+\delta\right)
\end{aligned}
$$

are satisfied for some $\delta$ with $0<\delta<\varepsilon$. This concludes the proof. 


\section{Section 6. Conclusion}

Lemma 6.1. Suppose $u \in C_{c}^{\infty}\left(R^{3}, R^{3}\right)$ satisfies $\sum_{i=1}^{3} \partial u_{i} / \partial x_{i}=0$ and the functions $p: R^{3} \rightarrow R, G=\left(G_{1}, G_{2}, G_{3}\right): R^{3} \rightarrow R^{3}$ are defined by

$$
p(x)=\int_{R^{3}} \sum_{i=1}^{3} \sum_{j=1}^{3} \frac{\partial u_{j}}{\partial x_{i}}(y) \frac{\partial u_{i}}{\partial x_{j}}(y)(4 \pi|x-y|)^{-1} d y \quad \text { and } \quad G=\nabla p .
$$

Then we have

$$
\lim _{x_{1} \rightarrow \infty} x_{1}^{4} G_{1}\left(x_{1}, 0,0\right)=3(4 \pi)^{-1} \int_{R^{3}}\left(u_{2}(x)\right)^{2}+\left(u_{3}(x)\right)^{2}-2\left(u_{1}(x)\right)^{2} d x,
$$

and there exists $C \in R$ such that $C>0$ and

$$
|G(x)| \leqq C|x|^{-4}, \quad|\nabla G(x)| \leqq C|x|^{-5} .
$$

Proof. We set $g(x)=(4 \pi|x|)^{-1}$ for $x \in R^{3}$. Integration by parts and the assumption $\sum_{i=1}^{3} \partial u_{i} / \partial x_{i}=0$ imply

$$
\begin{gathered}
G(x)=\int_{R^{3}} \sum_{i=1}^{3} \sum_{j=1}^{3} u_{j}(y) u_{i}(y) \frac{\partial^{2}(\nabla g)}{\partial x_{i} \partial x_{j}}(x-y) d y \quad \text { if } x \notin \operatorname{spt}(u), \\
\frac{\partial G}{\partial x_{k}}(x)=\int_{R^{3}} \sum_{i=1}^{3} \sum_{j=1}^{3} u_{j}(y) u_{i}(y) \frac{\partial^{3}(\nabla g)}{\partial x_{i} \partial x_{j} \partial x_{k}}(x-y) d y \quad \text { if } x \notin \operatorname{spt}(u) .
\end{gathered}
$$

Let $r$ be a positive real number such that $u(x)=0$ holds if $|x| \geqq r$. Then (6.4), (6.5) imply that $|x|^{4}|G(x)|$ and $|x|^{5}|\nabla G(x)|$ are bounded on the set $\{x:|x| \geqq 2 r\}$. Since (6.1) implies that these functions are also bounded on the compact set $\{x:|x| \leqq 2 r\}$, we conclude (6.3). Assertion (6.2) is a consequence of (6.4).

Lemma 6.2. Let $U$ be the open subset of $P$ defined by

$$
U=\left\{\left(x_{1}, x_{2}\right) \in R^{2}:\left|x_{1}\right|<1,1 / 8<x_{2}<7 / 8\right\} .
$$

There exist $f, z, F, K, A, B, C, D$ such that (6.7)-(6.15) are satisfied:

$$
\begin{gathered}
f \in C_{c}^{\infty}(P, R), \quad z=\left(z_{1}, z_{2}\right) \in C_{c}^{\infty}\left(P, R^{2}\right), \quad F=\left(F_{1}, F_{2}\right) \in C^{\infty}\left(R^{2}, R^{2}\right), \\
K \text { is compact } \operatorname{spt}(z) \subset K \subset U, \\
f \geqq 0, \quad f(x)=0 \quad \text { if } x \notin U, \quad f(x)>|z(x)| \quad \text { if } x \in U, \\
L(f)(x) \geqq 0 \quad \text { if } x \notin K, \quad L(f)(x)>0 \quad \text { if } x \in U \sim K, \\
x_{2} \frac{\partial z_{1}}{\partial x_{1}}\left(x_{1}, x_{2}\right)+x_{2} \frac{\partial z_{2}}{\partial x_{2}}\left(x_{1}, x_{2}\right)+z_{2}\left(x_{1}, x_{2}\right)=0, \\
\nabla(p[0, f]-p[z, f])(x)=F(x) \quad \text { if } x \in P, \\
A, B, C, D \text { are real numbers, B>0,C>0,D>0, } \\
F_{1}(A, 0)=B, \quad \text { if } x \in R, \text { then }\left|F_{1}(x, 0)\right| \leqq B \quad \text { and } \quad F_{2}(x, 0)=0,
\end{gathered}
$$




$$
\lim _{x \rightarrow \infty} x^{4} F_{1}(x, 0)=D, \text { if } x \in R^{2}, \text { then }|F(x)| \leqq C|x|^{-4} \text { and } \quad|\nabla F(x)| \leqq C|x|^{-5} \text {. }
$$

Proof. Let $k: R^{2} \rightarrow R^{2}$ be the function defined by

$$
k\left(x_{1}, x_{2}\right)=\left(-\left(x_{2}-1 / 2\right), x_{1}\right) \text { if } 1 / 16<\left(x_{1}^{2}+\left(x_{2}-1 / 2\right)^{2}\right)^{1 / 2}<1 / 8
$$

and $k\left(x_{1}, x_{2}\right)=0$ otherwise. Let $g \in C_{c}^{\infty}\left(R^{2}, R\right)$ satisfy

$$
g(x) \geqq 0, \quad g(x)=0 \quad \text { if }|x| \geqq 1 / 16, \quad\|g\|_{1}=1, \quad g(x)=g(y) \quad \text { if }|x|=|y| .
$$

Setting $z\left(x_{1}, x_{2}\right)=x_{2}^{-1}(k * g)\left(x_{1}, x_{2}\right)$ for $x \in P$, we obtain

$$
\begin{gathered}
z \in C_{c}^{\infty}\left(P, R^{2}\right), \quad \operatorname{spt}(z) \subset[-3 / 16,3 / 16] \times[5 / 16,11 / 16], \quad\|z\|_{\infty} \leqq 2 / 5, \\
z_{1}\left(x_{1}, x_{2}\right)=z_{1}\left(-x_{1}, x_{2}\right), \quad z_{2}\left(x_{1}, x_{2}\right)=-z_{2}\left(-x_{1}, x_{2}\right) \\
x_{2} \frac{\partial z_{1}}{\partial x_{1}}\left(x_{1}, x_{2}\right)+x_{2} \frac{\partial z_{2}}{\partial x_{2}}\left(x_{1}, x_{2}\right)+z_{2}\left(x_{1}, x_{2}\right)=\frac{\partial}{\partial x_{1}}\left(k_{1} * g\right)\left(x_{1}, x_{2}\right) \\
+\frac{\partial}{\partial x_{2}}\left(k_{2} * g\right)\left(x_{1}, x_{2}\right)=0
\end{gathered}
$$

Setting $a_{1}=-1, b_{1}=1, a_{2}=1 / 8, b_{2}=7 / 8$, we use Lemma 5.4 (with $1 / 16$ in place of the $d$ that appears there) to obtain the function $h$ and $\delta<1 / 16$. We then define

$$
f(x)=h(x) \text { if } x \in P, \quad K=\left\{\left(x_{1}, x_{2}\right):\left|x_{1}\right| \leqq 1-\delta, 1 / 8+\delta \leqq x_{2} \leqq 7 / 8-\delta\right\},
$$

and observe that the properties of $h, \delta<1 / 16,(6.6)$ and (6.16) imply

$$
\begin{array}{clll}
f \in C_{c}^{\infty}(P, R), \quad f(x)>0 & \text { if } x \in U, & f(x)=1 & \text { if } x \in \operatorname{spt}(z), \\
L(f)(x)>0 \quad \text { if } x \in U \sim K, & f(x)=0 & \text { if } x \notin U, & \operatorname{spt}(z) \subset K \subset U .
\end{array}
$$

Using (6.16), (6.20) we find

$$
f(x)>|z(x)| \text { if } x \in U .
$$

Assertions (6.16), (6.20)-(6.22) imply that the definition

$$
\begin{aligned}
F\left(x_{1}, x_{2}\right)=\left(F_{1}\left(x_{1}, x_{2}\right), F_{2}\left(x_{1}, x_{2}\right)\right)= & \frac{\partial}{\partial x_{1}}\left(p^{*}[0, f]-p^{*}[z, f]\right)\left(x_{1}, x_{2}, 0\right), \\
& \left.\frac{\partial}{\partial x_{2}}\left(p^{*}[0, f]-p^{*}[z, f]\right)\left(x_{1}, x_{2}, 0\right)\right)
\end{aligned}
$$

makes sense for $\left(x_{1}, x_{2}\right) \in R^{2}$. Using (6.16), (6.18) we obtain $\sum_{i=1}^{3}\left(\partial / \partial x_{i}\right) u_{i}[z, f]=0$. This fact, the identity $\sum_{i=1}^{3}\left(\partial / \partial x_{i}\right) u_{i}[0, f]=0,(6.16),(6.20)$ and Lemma 6.1 imply (6.24) and (6.25):

$$
\begin{aligned}
\lim _{x_{1} \rightarrow \infty} x_{1}^{4} F_{1}\left(x_{1}, 0\right)= & 3(4 \pi)^{-1} \int_{R^{3}}\left(u_{2}[0, f](x)\right)^{2}+\left(u_{3}[0, f](x)\right)^{2}-2\left(u_{1}[0, f](x)\right)^{2} d x \\
& -3(4 \pi)^{-1} \int_{R^{3}}\left(u_{2}[z, f](x)\right)^{2}+\left(u_{3}[z, f](x)\right)^{2} \\
& -2\left(u_{1}[z, f](x)\right)^{2} d x
\end{aligned}
$$




$$
\begin{aligned}
&= 3(4 \pi)^{-1} \int_{R^{3}}\left(f\left(x_{1},\left(x_{2}^{2}+x_{3}^{2}\right)^{1 / 2}\right)\right)^{2} d x_{1} d x_{2} d x_{3} \\
&-3(4 \pi)^{-1} \int_{R^{3}}\left(z_{2}\left(x_{1},\left(x_{2}^{2}+x_{3}^{2}\right)^{1 / 2}\right)\right)^{2} d x_{1} d x_{2} d x_{3} \\
&-3(4 \pi)^{-1} \int_{R^{3}}\left(f\left(x_{1},\left(x_{2}^{2}+x_{3}^{2}\right)^{1 / 2}\right)\right)^{2} \\
&-\left|z\left(x_{1},\left(x_{2}^{2}+x_{3}^{2}\right)^{1 / 2}\right)\right|^{2} d x_{1} d x_{2} d x_{3} \\
&-3(4 \pi)^{-1} \int_{R^{3}}-2\left(z_{1}\left(x_{1},\left(x_{2}^{2}+x_{3}^{2}\right)^{1 / 2}\right)\right)^{2} d x_{1} d x_{2} d x_{3} \\
&= 9(4 \pi)^{-1} \int_{R^{3}}\left(z_{1}\left(x_{1},\left(x_{2}^{2}+x_{3}^{2}\right)^{1 / 2}\right)\right)^{2} d x_{1} d x_{2} d x_{3}>0, \\
&|F(x)| \leqq C|x|^{-4}, \quad|\nabla F(x)| \leqq C|x|^{-5} \quad \text { for some } C<\infty .
\end{aligned}
$$

Using (6.24), (6.25) we find that the function $F_{1}\left(x_{1}, 0\right)$ of the variable $x_{1}$ achieves a positive maximum at some number $A$. Let $B$ be this maximum value. From (6.17) and (6.23) we obtain $F_{1}\left(-x_{1}, 0\right)=-F_{1}\left(x_{1}, 0\right)$ for all $x_{1} \in R$. All this implies

$$
F_{1}(A, 0)=B, \quad\left|F_{1}(x, 0)\right| \leqq B \quad \text { if } x \in R .
$$

Finally, (6.20), (6.16), (6.23) imply (6.7); (6.19), (6.21) imply (6.8); (6.20)-(6.22) imply (6.9); (6.6), (6.21) imply (6.10); (6.18) implies (6.11); (6.23) implies (6.12); and (6.13)-(6.15) follow from (6.23)-(6.26) and the fact $p^{*}[v, f]\left(R_{c} x\right)=p^{*}[v, f](x)$. The proof of the lemma is complete.

Now we tie together the results from Sects. 3,4,5. We will use the $U, f, z, F$, $K, A, B, C, D$ from Lemma 6.2. Since (6.7), (6.13)-(6.15) say that the hypotheses of Sect. 4 are satisfied, we can use the machinery developed in that section. In particular, we will use the function $w$ in Lemma 4.8 and the numbers $a, r, s, a^{\prime}$, $r^{\prime}, s^{\prime}, a^{\prime \prime}, r^{\prime \prime}, s^{\prime \prime}, E, \varepsilon, d$ introduced in Sect. 4 (see (4.7), (4.8), (4.18)-(4.21), Lemma 4.3).

When $\alpha \in R, \rho>0, \sigma>0$ we let

$$
f^{\alpha, \rho, \sigma} \in C_{c}^{\infty}(P, R) \quad \text { and } \quad z^{\alpha, \rho, \sigma}=\left(z_{1}^{\alpha, \rho, \sigma}, z_{2}^{\alpha, \rho, \sigma}\right) \in C_{c}^{\infty}\left(P, R^{2}\right)
$$

be given by

$$
\begin{aligned}
f^{\alpha, \rho, \sigma}\left(x_{1}, x_{2}\right) & =\sigma f\left(\left(x_{1}-\alpha\right) / \rho, x_{2} / \rho\right), \quad z^{\alpha, \rho, \sigma}\left(x_{1}, x_{2}\right) \\
& =\sigma z\left(\left(x_{1}-\alpha\right) / \rho, x_{2} / \rho\right) .
\end{aligned}
$$

If $\alpha \in R$ and $\rho>0$, we set

$$
\begin{aligned}
& U^{\alpha, \rho}=\left\{x \in R^{2}:\left(\left(x_{1}-\alpha\right) / \rho, x_{2} / \rho\right) \in U\right\}, \\
& K^{\alpha, \rho}=\left\{x \in R^{2}:\left(\left(x_{1}-\alpha\right) / \rho, x_{2} / \rho\right) \in K\right\} .
\end{aligned}
$$

We will use the notation

$$
\begin{aligned}
f_{1} & =f^{a, r, s}+f^{a^{\prime}, r^{\prime}, s^{\prime}}+f^{a^{\prime \prime}, r^{\prime \prime}, s^{\prime \prime}}+f, \\
v_{1} & =z^{a, r, s}+z^{a^{\prime}, r^{\prime}, s^{\prime}}+z^{a^{\prime \prime}, r^{\prime \prime}, s^{\prime \prime}}+z, \\
U_{1} & =U^{a, r} \cup U^{a^{\prime}, r^{\prime}} \cup U^{a^{\prime \prime}, r^{\prime \prime}} \cup U, \\
K_{1} & =K^{a, r} \cup K^{a^{\prime}, r^{\prime}} \cup K^{a^{\prime \prime}, r^{\prime \prime}} \cup K .
\end{aligned}
$$


Properties (6.9), (6.28), (6.29) imply

$$
\operatorname{spt}(f)=\operatorname{closure}(U), \quad \operatorname{spt}\left(f^{\alpha, \rho, \sigma}\right)=\operatorname{closure}\left(U^{\alpha, \rho}\right) .
$$

From (4.20), $0<\varepsilon<.01$ (see (4.19)), (4.23) and (4.21) we conclude

$$
a+r=-r \varepsilon^{-1} 10^{3} C / D+r<-r 10^{5} C / D+10^{-4} d=-10 d+10^{-4} d<-d .
$$

This inequality, (6.6), (6.29) and (6.31) imply

$$
\operatorname{spt}\left(f^{a, r, s}\right) \text { and }[-d, d] \times\left[10^{-3} \varepsilon r, r\right] \text { are disjoint. }
$$

Using (4.10), (4.11), $r / 10>1$ (see (4.22)), (6.6), (6.29), (6.31) we find

$$
\operatorname{spt}\left(f^{a^{\prime}, r^{\prime}, s^{\prime}}\right) \cup \operatorname{spt}\left(f^{a^{\prime \prime}, r^{\prime \prime}, s^{\prime \prime}}\right) \cup \operatorname{spt}(f) \subset R \times(E, r / 10) .
$$

From (4.8), (4.10) we get $\left|a^{\prime}\right|+r^{\prime}<|A|+1,\left|a^{\prime \prime}\right|+r^{\prime \prime}<|A|+1$. Properties (4.22), (4.23) imply $|A|+1<r / 10<d-r$. These facts, (6.6), (6.29), (6.31) and (6.33) yield

$$
\operatorname{spt}\left(f^{a^{\prime}, r^{\prime}, s^{\prime}}\right) \cup \operatorname{spt}\left(f^{a^{\prime \prime}, r^{\prime \prime}, s^{\prime \prime}}\right) \cup \operatorname{spt}(f) \subset(r-d, d-r) \times(E, r / 10) .
$$

In addition, (4.10), (6.6), (6.29), (6.31) yield

$$
\operatorname{spt}\left(f^{a^{\prime}, r^{\prime}, s^{\prime}}\right), \quad \operatorname{spt}\left(f^{a^{\prime \prime}, r^{\prime \prime}, s^{\prime \prime}}\right) \quad \text { and } \operatorname{spt}(f) \text { are disjoint. }
$$

From (4.22) and (4.24) we conclude

$$
[r-d, d-r] \times[E, r / 10] \subset(-d, d) \times\left(10^{-3} \varepsilon r, r\right) .
$$

Now (6.32), (6.34)-(6.36) yield

$$
\operatorname{spt}\left(f^{a, r, s}\right), \quad \operatorname{spt}\left(f^{a^{\prime}, r^{\prime}, s^{\prime}}\right), \quad \operatorname{spt}\left(f^{a^{\prime \prime}, r^{\prime \prime}, s^{\prime \prime}}\right) \quad \text { and } \operatorname{spt}(f) \text { are disjoint. }
$$

Properties (6.6)-(6.9), (6.28), (6.30), (6.37) imply

$$
\begin{gathered}
p\left[v_{1}, f_{1}\right]=p\left[z^{a, r, s}, f^{a, r, s}\right]+p\left[z^{a^{\prime}, r^{\prime}, s^{\prime}}, f^{a^{\prime}, r^{\prime}, s^{\prime}}\right]+p\left[z^{a^{\prime \prime}, r^{\prime \prime}, s^{\prime \prime}}, f^{a^{\prime \prime}, r^{\prime \prime}, s^{\prime \prime}}\right]+p[z, f], \\
p\left[0, f_{1}\right]=p\left[0, f^{a, r, s}\right]+p\left[0, f^{a^{\prime}, r^{\prime}, s^{\prime}}\right]+p\left[0, f^{a^{\prime \prime}, r^{\prime \prime}, s^{\prime \prime}}\right]+p[0, f] .
\end{gathered}
$$

Using (6.12), (6.28), (4.5) we conclude

$$
\nabla\left(p\left[0, f^{\alpha, \rho, \sigma}\right]-p\left[z^{\alpha, \rho, \sigma}, f^{\alpha, \rho, \sigma}\right]\right)(x)=F^{\alpha, \rho, \sigma}(x) \quad \text { if } x \in P .
$$

From (6.12) and (6.38)-(6.40) we get

$$
\nabla\left(p\left[0, f_{1}\right]-p\left[v_{1}, f_{1}\right]\right)(x)=\left(F^{a, r, s}+F^{a^{\prime}, r^{\prime}, s^{\prime}}+F^{a^{\prime \prime}, r^{\prime \prime}, s^{\prime \prime}}+F\right)(x) \text { if } x \in P .
$$

Recalling (6.36), we set

$$
U_{2}=\left((-d, d) \times\left(10^{-3} \varepsilon r, r\right)\right) \sim([r-d, d-r] \times[E, r / 10]) \subset P .
$$

The proof of (6.36) shows that we can find $d_{1}>0$ satisfying $2 d_{1}<d-(d-r), 2 d_{1}<$ $E-10^{-3} \varepsilon r, 2 d_{1}<r-r / 10$. Since Lemma 4.8 says $\operatorname{spt}(w) \subset U_{2}$ (see (6.42)), we can assume that $d_{1}$ is small enough to yield

$$
\operatorname{spt}(w) \subset\left(-d+d_{1}, d-d_{1}\right) \times\left(10^{-3} \varepsilon r+d_{1}, r-d_{1}\right),
$$

$\operatorname{spt}(w)$ and $\left[r-d-d_{1}, d-r+d_{1}\right] \times\left[E-d_{1}, r / 10+d_{1}\right]$ are disjoint. 
We let $h$ be the function of Lemma 5.4 which is obtained when $a_{1}=-d, b_{1}=d$, $a_{2}=10^{-3} \varepsilon r, b_{2}=r$ and the number $d$ in the statement of that lemma is equal to $d_{1}$. Similarly, we let $g$ be the function of Lemma 5.5 which is obtained when $a_{1}=r-d, b_{1}=d-r, a_{2}=E, b_{2}=r / 10$ and the number $d$ in the statement of Lemma 5.5 is equal to $d_{1}$. Setting $k(x)=h(x) g(x)$, we find that there exists $K_{2}$ satisfying (6.43)(6.45):

$$
\begin{gathered}
\operatorname{spt}(w) \subset K_{2} \subset U_{2}, \quad K_{2} \text { is compact, } \quad k \in C_{c}^{\infty}(P, R), \quad 0 \leqq k \leqq 1, \\
k(x)=0 \quad \text { if } x \notin U_{2}, \quad k(x)>0 \quad \text { if } x \in U_{2}, \quad k(x)=1 \quad \text { if } x \in \operatorname{spt}(w), \\
L(k)(x) \geqq 0 \quad \text { if } x \notin K_{2}, \quad L(k)(x)>0 \quad \text { if } x \in U_{2} \sim K_{2} .
\end{gathered}
$$

We choose $\mu>0$ large enough to satisfy

$$
\begin{aligned}
\mu^{2} & >10\left(\|w\|_{\infty}^{2}+1\right), \\
\mu>100\left\|f^{a, r, s}\right\|_{\infty} \quad \text { and } \quad \mu & >10\left(\left\|f^{a^{\prime}, r^{\prime}, s^{\prime}}\right\|_{\infty}+\left\|f^{a^{\prime \prime}, r^{\prime \prime}, s^{\prime \prime}}\right\|_{\infty}+\|f\|_{\infty}\right) .
\end{aligned}
$$

Noting that (6.46) implies $\mu^{2}-\|w\|_{\infty}^{2}-1>0$, we set

$$
f_{2}=\mu k, \quad v_{2}=w, \quad T=\left(\mu^{2}-\left\|v_{2}\right\|_{\infty}^{2}-1\right) /\left(\varepsilon^{2}(1.032) B\right)>0, \quad \tau=(.48) \varepsilon .
$$

If $x \in \operatorname{spt}\left(v_{2}\right)=\operatorname{spt}(w)$, then (6.48), (6.44), (6.41), $v_{2}=w, T>0$ and Lemma 4.8 (in particular, (4.30)) yield

$$
\begin{aligned}
& \left(f_{2}(x)\right)^{2}-T v_{2}(x) \cdot \nabla\left(p\left[v_{1}, f_{1}\right]-p\left[0, f_{1}\right]\right)(x) \\
& \quad=\mu^{2}+T w(x) \cdot\left(F^{a, r, s}+F^{a^{\prime}, r^{\prime}, s^{\prime}}+F^{a^{\prime \prime}, r^{\prime \prime}, s^{\prime \prime}}+F\right)(x) \\
& \quad \geqq \mu^{2}-T \varepsilon^{2}(1.032) B=\left\|v_{2}\right\|_{\infty}^{2}+1>\left|v_{2}(x)\right|^{2} .
\end{aligned}
$$

If $x \in U_{2}$ and $x \notin \operatorname{spt}\left(v_{2}\right)=\operatorname{spt}(w)$, then (6.48), (6.44) and $\mu>0$ imply

$$
\left(f_{2}(x)\right)^{2}-T v_{2}(x) \cdot \nabla\left(p\left[v_{1}, f_{1}\right]-p\left[0, f_{1}\right]\right)(x)=\left(f_{2}(x)\right)^{2}=\mu^{2}(k(x))^{2}>0=\left|v_{2}(x)\right|^{2} \text {. }
$$

All this shows

$$
\left(f_{2}(x)\right)^{2}-T v_{2}(x) \cdot \nabla\left(p\left[v_{1}, f_{1}\right]-p\left[0, f_{1}\right]\right)(x)>\left|v_{2}(x)\right|^{2} \quad \text { if } x \in U_{2} .
$$

Conditions (6.46) and (6.48) imply

$$
\mu^{2}-\left\|v_{2}\right\|_{\infty}^{2}-1>(.9) \mu^{2}, \text { hence } T>(.9) \mu^{2} /\left(\varepsilon^{2}(1.032) B\right) \text {. }
$$

Now (6.50), (6.48), (6.47) yield

$$
\begin{aligned}
& \left(\mu^{2}+T(8.01) B\right)^{1 / 2}>(T(8.01) B)^{1 / 2}>\left[(.9) \mu^{2}(8.01) /\left(\varepsilon^{2}(1.032)\right)\right]^{1 / 2}>((.48) \varepsilon)^{-1}(1.1) \mu \\
& =\tau^{-1}(1.1) \mu>\tau^{-1}\left(\left\|f^{a^{\prime}, r^{\prime}, s^{\prime}}\right\|_{\infty}+\left\|f^{a^{\prime \prime}, r^{\prime \prime}, s^{\prime \prime}}\right\|_{\infty}+\|f\|_{\infty}+\mu\right) .
\end{aligned}
$$

Similarly, (6.50), (6.48), (6.47) yield

$$
\begin{aligned}
\left(\mu^{2}+T(.01) B\right)^{1 / 2} & >(T(.01) B)^{1 / 2}>\left[(.9) \mu^{2}(.01) /\left(\varepsilon^{2}(1.032)\right)\right]^{1 / 2} \\
& >((.48) \varepsilon)^{-1}(\mu / 100)=\tau^{-1}(\mu / 100)>\tau^{-1}\left\|f^{a, r, s}\right\|_{\infty} .
\end{aligned}
$$

Assertions (6.51), (6.52) allow us to choose $\theta>0$ such that (6.53), (6.54) hold:

$$
\left(\mu^{2}+T(8.01) B\right)^{1 / 2}-\theta>\tau^{-1}\left(\left\|f^{a^{\prime}, r^{\prime}, s^{\prime}}\right\|_{\infty}+\left\|f^{a^{\prime \prime}, r^{\prime \prime}, s^{\prime \prime}}\right\|_{\infty}+\|f\|_{\infty}+\mu\right) .
$$




$$
\left(\mu^{2}+T(.01) B\right)^{1 / 2}-\theta>\tau^{-1}\left\|f^{a, r, s}\right\|_{\infty} .
$$

Lemma 6.3. The parameters $T, \theta, K_{1}, K_{2}, U_{1}, U_{2}, f_{1}, f_{2}, v_{1}, v_{2}$ defined above satisfy $T>0, \theta>0$ and (3.1)-(3.7).

Proof. This follows from (6.27)-(6.49) and the definition of $\theta$.

The above lemma says that all the hypotheses of Sect. 3 are satisfied. We will now use the machinery developed in that section. In what follows, we refer to the functions $h_{i}$ and $h_{i, t}$ that are featured in Lemmas 3.1, 3.3.

Lemma 6.4. Let $h_{1}, h_{2}$ be the functions that were introduced in Lemma 3.1. Set $h_{3}=h_{1}+h_{2}$ and $h_{3, t}(x)=h_{3}(x, t)$ for $t \in[0, T]$. If $\left(x_{1}, x_{2}, x_{3}\right) \in R^{3}$ and $\left(x_{1}\right.$, $\left.\left(x_{2}^{2}+x_{3}^{2}\right)^{1 / 2}\right) \in \operatorname{spt}\left(h_{3,0}\right)$, then $\left(\tau x_{2}+\varepsilon r / 2\right)^{2}+\left(\tau x_{3}\right)^{2}>0$ and

$$
h_{3, T}\left(\tau x_{1}+A,\left(\left(\tau x_{2}+\varepsilon r / 2\right)^{2}+\left(\tau x_{3}\right)^{2}\right)^{1 / 2}\right)>\tau^{-1} h_{3,0}\left(x_{1},\left(x_{2}^{2}+x_{3}^{2}\right)^{1 / 2}\right) .
$$

Proof. Part (4.29) of Lemma 4.8, B>0, (6.48), (3.1) and (3.3) (see Lemma 6.3) imply

$$
[r-d, d-r] \times[(.02) \varepsilon r,(.98) \varepsilon r] \subset \operatorname{spt}(w)=\operatorname{spt}\left(v_{2}\right) \subset U_{2} .
$$

Properties (3.4), (3.9), (3.11) imply $h_{1}(y, t)=0$ for $y \notin U_{1}$. This fact, (6.55), and the disjointness of $U_{1}, U_{2}$ (see (3.3)) imply

$$
\text { if }\left|y_{1}\right| \leqq d-r \text { and }(.02) \varepsilon r \leqq y_{2} \leqq(.98) \varepsilon r, \quad \text { then } h_{1}\left(y_{1}, y_{2}, T\right)=0 \text {. }
$$

Using (3.12), (3.13), $f_{i} \geqq 0, h_{i} \geqq 0$ (see (3.4), (3.10)), (6.30) we find

$$
h_{3,0}=f_{1}+f_{2}=f^{a, r, s}+f^{a^{\prime}, r^{\prime}, s^{\prime}}+f^{a^{\prime \prime}, r^{\prime \prime}, s^{\prime \prime}}+f+f_{2} .
$$

Suppose $\left(x_{1},\left(x_{2}^{2}+x_{3}^{2}\right)^{1 / 2}\right) \in \operatorname{spt}\left(h_{3,0}\right)$. Then (6.57), (6.31), (6.29), (6.6), (6.34), (6.36), (6.48), (6.44), (6.42) imply that either Case 1 or Case 2 is satisfied:

Case 1: $\left(x_{1},\left(x_{2}^{2}+x_{3}^{2}\right)^{1 / 2}\right) \in \operatorname{spt}\left(f^{a, r, s}\right)=\operatorname{closure}\left(U^{a, r}\right)=[a-r, a+r] \times[r / 8,7 r / 8]$,

Case 2: $\left(x_{1},\left(x_{2}^{2}+x_{3}^{2}\right)^{1 / 2}\right) \in \operatorname{spt}\left(f^{a^{\prime}, r^{\prime}, s^{\prime}}\right) \cup \operatorname{spt}\left(f^{a^{\prime \prime}, r^{\prime \prime}, s^{\prime \prime}}\right) \cup \operatorname{spt}(f) \cup \operatorname{spt}\left(f_{2}\right) \subset[-d, d] \times$ $\left[10^{-3} \varepsilon r, r\right]$.

In either case, we have $\left(x_{2}^{2}+x_{3}^{2}\right)^{1 / 2} \leqq r$. This fact, (6.48), and the general inequality

$$
-\left(x^{2}+z^{2}\right)^{1 / 2}+y \leqq\left((x+y)^{2}+z^{2}\right)^{1 / 2} \leqq\left(x^{2}+z^{2}\right)^{1 / 2}+y \quad \text { if } y>0
$$

imply

$$
\begin{aligned}
0<(.02) \varepsilon r & =-\tau r+\varepsilon r / 2 \leqq-\left(\left(\tau x_{2}\right)^{2}+\left(\tau x_{3}\right)^{2}\right)^{1 / 2}+\varepsilon r / 2 \\
& \leqq\left(\left(\tau x_{2}+\varepsilon r / 2\right)^{2}+\left(\tau x_{3}\right)^{2}\right)^{1 / 2} \leqq\left(\left(\tau x_{2}\right)^{2}+\left(\tau x_{3}\right)^{2}\right)^{1 / 2}+\varepsilon r / 2 \leqq \tau r+\varepsilon r / 2 \\
& =(.98) \varepsilon r .
\end{aligned}
$$

In particular, (6.58) gives us $\left(\tau x_{2}+\varepsilon r / 2\right)^{2}+\left(\tau x_{3}\right)^{2}>0$. In both cases we also have $\left|x_{1}\right|<|a|+r+d$. Using this fact, (6.48), (4.20), (4.22), (4.21), (4.19) and (4.23) we find

$$
\begin{aligned}
\left|\tau x_{1}+A\right| & \leqq \tau\left|x_{1}\right|+|A| \leqq \tau(|a|+r+d)+|A| \\
& \leqq(.48) \varepsilon r \varepsilon^{-1} 10^{3} C / D+(.48) \varepsilon(r+d)+r / 20 \\
& \leqq(.048) d+(.0048)(1.0001) d+10^{-4} d / 20<d-r .
\end{aligned}
$$


From (6.58), (6.59), (6.55), (6.44), (6.48) we conclude

$$
f_{2}\left(\tau x_{1}+A,\left(\left(\tau x_{2}+\varepsilon r / 2\right)^{2}+\left(\tau x_{3}\right)^{2}\right)^{1 / 2}\right)=\mu .
$$

Properties (6.48), (6.44), (6.42), (6.32), (6.34), (6.37) yield

$$
\operatorname{spt}\left(f^{a, r, s}\right), \operatorname{spt}\left(f^{a^{\prime}, r^{\prime}, s^{\prime}}\right), \operatorname{spt}\left(f^{a^{\prime \prime}, r^{\prime \prime}, s^{\prime \prime}}\right), \operatorname{spt}(f), \operatorname{spt}\left(f_{2}\right) \text { are disjoint. }
$$

Recalling (6.58), we set

$$
\left(y_{1}, y_{2}\right)=\left(\tau x_{1}+A,\left(\left(\tau x_{2}+\varepsilon r / 2\right)^{2}+\left(\tau x_{3}\right)^{2}\right)^{1 / 2}\right) \in P .
$$

From (6.62), (3.14), (6.60), (6.48) and (6.41) we conclude

$$
\begin{aligned}
& h_{2}\left(y_{1}, y_{2}, T\right)+\theta>\left(\left(f_{2}\left(y_{1}, y_{2}\right)\right)^{2}-T v_{2}\left(y_{1}, y_{2}\right) \cdot \nabla\left(p\left[v_{1}, f_{1}\right]-p\left[0, f_{1}\right]\right)\left(y_{1}, y_{2}\right)\right)^{1 / 2} \\
& \quad=\left(\mu^{2}+T w\left(y_{1}, y_{2}\right) \cdot\left(F^{a, r, s}+F^{a^{\prime}, r^{\prime}, s^{\prime}}+F^{a^{\prime \prime}, r^{\prime \prime}, s^{\prime \prime}}+F\right)\left(y_{1}, y_{2}\right)\right)^{1 / 2}
\end{aligned}
$$

Properties (6.56), (6.58), (6.59), (6.62) imply

$$
h_{3, T}\left(y_{1}, y_{2}\right)=h_{1}\left(y_{1}, y_{2}, T\right)+h_{2}\left(y_{1}, y_{2}, T\right)=h_{2}\left(y_{1}, y_{2}, T\right) \text {. }
$$

Now suppose that Case 1 holds. Using (6.63), part (4.29) of Lemma 4.8, (6.58), (6.59), (6.54), (6.61) and (6.57) we obtain

$$
\begin{aligned}
& h_{2}\left(y_{1}, y_{2}, T\right)+\theta>\left(\mu^{2}+T(.01) B\right)^{1 / 2}>\theta+\tau^{-1}\left\|f^{a, r, s}\right\|_{\infty} \\
& \quad \geqq \theta+\tau^{-1} f^{a, r, s}\left(x_{1},\left(x_{2}^{2}+x_{3}^{2}\right)^{1 / 2}\right)=\theta+\tau^{-1}\left(f_{1}+f_{2}\right)\left(x_{1},\left(x_{2}^{2}+x_{3}^{2}\right)^{1 / 2}\right) \\
& \quad=\theta+\tau^{-1} h_{3,0}\left(x_{1},\left(x_{2}^{2}+x_{3}^{2}\right)^{1 / 2}\right) .
\end{aligned}
$$

The above and (6.64) yield

Case 1 implies $h_{3, T}\left(y_{1}, y_{2}\right)>\tau^{-1} h_{3,0}\left(x_{1},\left(x_{2}^{2}+x_{3}^{2}\right)^{1 / 2}\right)$.

On the other hand, suppose that Case 2 holds. This implies $\left|x_{1}\right| \leqq d$. This fact, (6.48), (4.21) and (4.22) yield

$$
\left|\left(\tau x_{1}+A\right)-A\right|=\tau\left|x_{1}\right| \leqq \tau d=(.48) \varepsilon r 10^{4} C / D<E\left(10^{4} C / D\right) .
$$

Now (6.63), part (4.28) of Lemma 4.8, (6.58), the above inequality, (6.53), (6.43), (6.48), (6.61) and (6.57) yield

$$
\begin{aligned}
h_{2}\left(y_{1}, y_{2}, T\right)+\theta & >\left(\mu^{2}+T(8.01) B\right)^{1 / 2} \\
& >\theta+\tau^{-1}\left(\left\|f^{a^{\prime}, r^{\prime}, s^{\prime}}\right\|_{\infty}+\left\|f^{a^{\prime \prime}, r^{\prime \prime}, s^{\prime \prime}}\right\|_{\infty}+\|f\|_{\infty}+\left\|f_{2}\right\|_{\infty}\right) \\
& \geqq \theta+\tau^{-1}\left(f^{a^{\prime}, r^{\prime}, s^{\prime}}+f^{a^{\prime \prime}, r^{\prime \prime}, s^{\prime \prime}}+f+f_{2}\right)\left(x_{1},\left(x_{2}^{2}+x_{3}^{2}\right)^{1 / 2}\right) \\
& =\theta+\tau^{-1}\left(f_{1}+f_{2}\right)\left(x_{1},\left(x_{2}^{2}+x_{3}^{2}\right)^{1 / 2}\right) \\
& =\theta+\tau^{-1} h_{3,0}\left(x_{1},\left(x_{2}^{2}+x_{3}^{2}\right)^{1 / 2}\right) .
\end{aligned}
$$

This inequality and (6.64) yield

$$
\text { Case } 2 \text { implies } h_{3, T}\left(y_{1}, y_{2}\right)>\tau^{-1} h_{3,0}\left(x_{1},\left(x_{2}^{2}+x_{3}^{2}\right)^{1 / 2}\right) \text {. }
$$

The conclusion of the lemma follows from (6.58), (6.62), (6.65), (6.66).

Finally, Theorem 1.1 is a consequence of Lemma 6.4, Lemma 3.3 and Lemma 2.4. 


\section{References}

1. Caffarelli, L., Kohn, R., Nirenberg, L.: Partial regularity of suitable weak solutions of the NavierStokes equations. Comm. Pure Appl. Math. 35, 771-831 (1982)

2. Conte, S. D., de Boor, C.: Elementary numerical analysis, an algorithmic approach, 3rd ed. New York: McGraw-Hill 1980

3. Federer, H.: Geometric measure theory. Berlin, Heidelberg, New York: Springer 1969

4. Scheffer, V.: Hausdorff measure and the Navier-Stokes equations. Commun. Math. Phys. 55, 97-112 (1977)

Communicated by L. Nirenberg

Received July 17, 1984; in revised form January 10, 1985 
